\title{
MRPL35 Is Up-Regulated in Colorectal Cancer and Regulates Colorectal Cancer Cell Growth and Apoptosis
}

Litao Zhang, * Peifen Lu, * Lihong Yan, * Lijun Yang, ${ }^{\dagger}$ Yutao Wang, ${ }^{*}$ Junjun Chen, ${ }^{*}$ Jie Dai, ${ }^{*}$ Yahui Li, ${ }^{*}$ Zhiming Kang, * Tao Bai, Yanfeng $\mathrm{Xi}^{\ddagger}$, Jun $\mathrm{Xu}^{\natural}$ " Gongqin Sun, ${ }^{* \|}$ and Tao Yang*

From the Departments of Biochemistry \& Molecular Biology* and Pharmacology, ${ }^{\dagger}$ Shanxi Medical University, Taiyuan, China; the Department of Pathology, ${ }^{\ddagger}$ First Affiliated Hospital of Shanxi Medical University, Taiyuan, China; the Department of Pathology, ${ }^{\S}$ Shanxi Provincial Cancer Hospital, Taiyuan, China; the Department of General Surgery, "Shanxi Grand Hospital, Taiyuan, China; and the Department of Cell and Molecular Biology," University of Rhode Island, Kingston, Rhode Island

\author{
Accepted for publication \\ February 5, 2019. \\ Address correspondence to \\ Tao Yang, Ph.D., No.56 Xin- \\ jian S. Rd., Taiyuan, Shanxi \\ 030001, China; or Gongqin \\ Sun, Ph.D., 120 Flag Rd., \\ Kingston, RI 02881. E-mail: \\ yangtao056cn@126.com or \\ gongqinsun@uri.edu.
}

\begin{abstract}
Mitochondrial ribosome proteins (MRPs), which are encoded by the nuclear genomic DNA, are important for mitochondrial-encoded protein synthesis and mitochondrial function. Emerging evidence suggests that several MRPs also exhibit important extra-mitochondrial functions, such as involvement in apoptosis, protein biosynthesis, and signal transduction. In this study, we demonstrate a significant role of MRP L35 (MRPL35) in colorectal cancer (CRC). The expression of MRPL35 was higher in CRC tissues than in matched cancer-adjacent tissues and higher in CRC cells than in normal mucosal epithelial cells. Higher MRPL35 expression in CRC tissue correlated with shorter overall survival for CRC patients. In vitro, down-regulation of MRPL35 led to increased production of reactive oxygen species (ROS) together with DNA damage, loss of cell proliferation, $G_{2} / M$ arrest, a decrease in mitochondrial membrane potential, apoptosis, and autophagy induction. MRPL35 knockdown inhibited tumor proliferation in a CRC xenograft nude mouse model. Furthermore, overexpression of MRPL35 or treatment of cells with the ROS scavenger, $\mathrm{N}$-acetyl cysteine, abrogated ROS production, cell cycle arrest, and apoptosis in vitro. These findings suggest that MRPL35 plays an essential role in the development of CRC and may be a potential therapeutic target for CRC. (Am J Pathol 2019, 189: 1105-1120; https:// doi.org/10.1016/j.ajpath.2019.02.003)
\end{abstract}

Colorectal cancer (CRC), characterized by fast progression and poor prognosis, is one of the most common malignancies in the world. ${ }^{1}$ The mechanisms of CRC development are still poorly understood. Although surgery is the most effective therapy for $\mathrm{CRC}$, chemotherapy and radiotherapy are still indispensable. ${ }^{2}$ Side effects and drug resistance are common issues with most of these treatments reducing their efficacy. As a consequence, $\mathrm{CRC}$ is in urgent need of markers for early diagnosis and of intervention targets for effective therapy.

Mitochondria have a central role in cellular energy metabolism by oxidative phosphorylation, regulation of apoptosis, autophagy, and cell death. ${ }^{3-5}$ Defective mitochondrial functions have been thought to be possible underlying mechanisms for cancer., Mitochondria have their own DNA and ribosomes (mitoribosomes), which produce 13 proteins essential for oxidative phosphorylation. ${ }^{8}$ Human mitoribosomes sediment as $55 \mathrm{~S}$ particles, consisted of a $28 \mathrm{~S}$ small subunit, formed by a $12 \mathrm{~S}$ rRNA and 29 mitochondrial ribosome proteins (MRPs), and a 39S large subunit, formed by a 16S rRNA and 50 MRPs. ${ }^{9,10}$ The approximately 70 MRPs are encoded by nuclear genomic DNA, synthesized in the cytosol,

\footnotetext{
Supported by the National Natural Science Foundation of China grants 81101895 and 81441021, the Shanxi Scholarship Council of China grant 2016-050, and the Program for the Scientific Activities of Selected Returned Overseas Professionals in Shanxi Province grant 2014-779.

L.Z., P.L., and L.Yan contributed equally to this work.

Disclosures: None declared.
} 
imported into the mitochondrial matrix, and assembled into mitoribosomes. ${ }^{10}$

Studies indicate that the level of expression of many MRP genes is altered in different cancer types, and changes in their expression are correlated with various clinical features in some cancers. ${ }^{9}$ High expression of MRPS23 stimulates cell proliferation and correlates to poor prognosis in hepatocellular carcinoma. ${ }^{11}$ MRPS29 (DAP3) and MRPS30 (PDCD9) are involved in promoting apoptosis in mammalian cells. ${ }^{12}$ The MRPL33-L isoform can promote cancer cell growth and repress apoptosis in colorectal tumor development. ${ }^{13}$ MRPL41 is either expressed at reduced levels or absent in most tumor types and cell lines, and its expression suppresses tumor cell growth. ${ }^{14}$ Several studies suggested possible regulatory mechanisms of MRPs in cancer. As a potential mechanism for its role in cell growth control, MRPL10 regulates cyclin B1/Cdk1 activity in mammalian cells. ${ }^{15}$ Down-regulation of MRPS23 and overexpression of MRPS36 delay cell cycle progression in association with $\mathrm{p} 53$ modification and $\mathrm{p} 21^{\mathrm{WAF} 1 / \mathrm{CIP} 1}$ expression, ${ }^{16,17}$ whereas MRPL41 is involved in cell proliferation regulation through the $\mathrm{p} 53$ and $\mathrm{p} 27^{\mathrm{kip} 1}$ pathway. ${ }^{14}$

Mitochondrial ribosomal protein L35 (MRPL35) is a 25$\mathrm{kDa}$ protein encoded by the MRPL35 gene located at 2p11.2. MRPL35 plays a key role in coordinating the synthesis and assembly of the cytochrome $c$ oxidase complex in the yeast model Saccharomyces cerevisiae and thus serves as a link between the mitochondrial translation apparatus and the downstream oxidative phosphorylation assembly. ${ }^{18}$ Here, we investigate the expression and biological significance of MRPL35 in CRC and demonstrate that MRPL35 is overexpressed in CRC tissues and cells. MRPL35 knockdown inhibits cell proliferation and survival in vivo and in vitro. We also characterize the molecular mechanisms to show that the down-regulation of MRPL35 leads to increased reactive oxygen species (ROS) production which correlates with DNA damage to suppress the progression of CRC.

\section{Materials and Methods}

\section{Reagents}

QIAprep Spin Mini prep Kit (250) was purchased from Qiagen (Hilden, Germany) and jetPRIME DNA Transfection Reagent was purchased from Polyplus (Illkirch, France). DAPI Staining Solution was purchased from Boster (Wuhan, China). $N$-Acetyl-L-cysteine (NAC) was purchased from Solarbio (Beijing, China). Caspase Inhibitor Z-VAD-FMK was obtained from Beyotime (Shanghai, China).

\section{CRC Tissue Microarray and IHC Analysis}

The tissue microarray contained $151 \mathrm{CRC}$ samples and matched cancer-adjacent tissues, obtained from the Department of Pathology of the First Affiliated Hospital of Shanxi
Medical University (Shanxi, China), from 2005 to 2010. Each tissue was selected to be $0.2 \mathrm{~cm}$ in diameter and $4 \mu \mathrm{m}$ in thickness. To determine the prognostic value of MRPL35, all samples were analyzed in relation to detailed survival data. The sections were dewaxed with xylene solution and gradient ethanol and were gradually hydrated. $\mathrm{H}_{2} \mathrm{O}_{2}(3 \%)$ was used to inactivate endogenous peroxidases. The sections were boiled in $0.01 \mathrm{~mol} / \mathrm{L}$ citrate buffer $(\mathrm{pH} 6)$ for 3 minutes for antigen retrieval. Then, the sections were incubated with a specific rabbit antibody diluted at 1:200 (MRPL35; Abnova, Taipei, Taiwan) for 1 hour at $37^{\circ} \mathrm{C}$ and 30 minutes at room temperature, and incubated with biotinylated anti-rabbit secondary antibody at $37^{\circ} \mathrm{C}$. Finally, the sections were visualized with diaminobenzidine of the DAB-0031 Kit (MXB, Fuzhou, China), and hematoxylin was used to counterstain the nuclei. Finally, the tissue microarray was dehydrated in gradient ethanol and xylene solution and then was sealed with neutral gum and observed under a microscope. The same method of immunohistochemistry (IHC) was used for the mouse tissues after sectioning.

\section{Analysis and Quantification of Staining}

Two pathologists (Y.X. and J.X.) examined the immunohistochemical staining using a double-blind method. The staining intensity (SI) was scored as follows: negative $=0$, weak $=1$ (I), moderate $=2$ (II), and strong $=3$ (III). The percentage of positively (PP) stained cells was scored as follows: 0 (negative), 1 (1\% to $25 \%$ ), 2 (26\% to $50 \%$ ), 3 (51\% to $75 \%$ ), and 4 ( $76 \%$ to $100 \%$ ). The immunoreactive score (IRS) was calculated using the following equation: IRS $=\mathrm{SI} \times \mathrm{PP}$.

An IRS $>6$ was defined as high expression and an IRS of $\leq 6$ was defined as low expression.

\section{Cell Lines and Tumor Tissues}

Cell lines (HCT116, HCT15, SW620, LS174T, Lovo, SW480, HT29) used in these experiments were purchased from Shanghai Institutes for Biological Sciences (Shanghai, China). Fresh tumor tissues and paired adjacent tissues (seven pairs of ascending colon, nine pairs of descending colon, six pairs of sigmoid colon, and four pairs of rectum) were obtained from $26 \mathrm{CRC}$ patients who underwent surgery at the First Affiliated Hospital of Shanxi Medical University and the Shanxi Provincial Cancer Hospital (Shanxi, China).

\section{Lentiviral Infection and Plasmid Transfection}

Lentiviral particles of MPRL35 (shMRPL35) were designed and produced by GeneChem (Shanghai, China). The shRNA sequence targeting MRPL35 was as follows: 5'-GTCAAGAATGCCTCTCTTA-3'. For overexpression studies, plasmid DNA (GV147/MRPL35) with the restriction enzyme cutting site $\mathrm{XhoI} / \mathrm{KpnI}$ was produced by GeneChem. 
Lentiviral infection and the specific steps for plasmid transfection were performed according to the supplier's protocol.

\section{RNA Extraction and RT-qPCR}

Total RNA was isolated using Trizol reagent (Thermo Fisher Scientific, Shanghai, China), according to the manufacturer's instructions. The mRNA levels were determined by TransStart Tip Green qPCR SuperMix (TransGen Biotech, Beijing, China) on a StepOne RT-qPCR instrument (ABI, Waltham, MA). All measurements were performed three times. The following primers were used: MRPL35, forward $5^{\prime}$ TTGGCATCTTCAACCTACCGC- $3^{\prime}$ and reverse $5^{\prime}$ GGAGGAAACAACTGGTGTCTGA-3'; $\beta$-actin, forward $5^{\prime}$-CTCACCATGGATGATGATATCGC- ${ }^{\prime}$ and reverse $5^{\prime}$ AGGAATCCTTCTGACCCATGC- ${ }^{\prime}$.

\section{Western Blot Analysis}

Total protein extracts were isolated from cells and fresh tumor tissues in RIPA lysis buffer (Beyotime) containing a protease inhibitor (Bioscience, Beijing, China) and a phosphatase inhibitor (Boster). Mitochondria isolation and protein extraction were performed by the Cell Mitochondria Isolation Kit (Beyotime). Nuclear and cytoplasmic proteins were extracted by the Nuclear and Cytoplasmic Protein Extraction Kit (Beyotime). Protein concentrations were measured using the BCA Protein Assay Kit (Beyotime). Proteins were separated by $6 \%$ to $12 \%$ SDS-PAGE and transferred to nitrocellulose membranes. Primary antibodies were diluted using Primary Antibody Dilution Buffer (Beyotime), whereas anti-mouse or anti-rabbit secondary antibodies were diluted using tris-buffered saline and Tween 20. Primary antibodies included MRPL35 (dilution 1:200) from LSBio (Seattle, WA); and Phospho-H2A.X (Ser139; 20E3; dilution 1:1000), Phospho-ataxia-telangiectasia mutated (ATM; Ser1981; D6H9; dilution 1:500), caspase-3 (dilution 1:400), cleaved-caspase-9 (dilution 1:500), cleaved-poly (ADP-ribose) polymerase (PARP; D64E10; dilution 1:500), Bcl-1-associated $\mathrm{X}$ protein (Bax; dilution 1:500), cytochrome $c$ (136F3; dilution 1:500), phospho-p53 (Ser15) (16G8; dilution 1:500), P21 Waf1/Cip1 (12D1; dilution 1:500), cyclin B1 (D5C10; dilution 1:500), phospho-cdc2 (Tyr15; 10A11; dilution 1:500), phosphoWee1 (Ser642) (D47G5; dilution 1:1000), histone H3 (dilution 1:1000), phospho-Chk1 (Ser345) (133D3; dilution 1:500), phospho-Chk2 (Thr68; C13C1; dilution 1:500), Atg5 (D5F5U; dilution 1:1000) from Cell Signaling Technology (Danvers, MA); DNA damage regulated autophagy modulator 1 (DRAM1; dilution 1:1000) from Novus Biologicals (Shanghai, China); glyceraldehyde-3-phosphate dehydrogenase (dilution 1:1000) from Sangon (Shanghai, China). All these antibodies were specific rabbit monoclonal antibodies, except that phospho-p53 was the specific mouse monoclonal antibody.

\section{Cell Cycle and Apoptosis Analysis}

Cell cycle analysis by flow cytometry was performed using the Cell Cycle Kit (KeyGEN BioTECH, Nanjing, China). Apoptosis detection by flow cytometry [FACSCalibur; Becton Dickinson Biosciences (BD Biosciences), San Jose, CA] was performed using the Annexin V-allophycocyanin/7aminoactinomycin D Cell Apoptosis Kit (KeyGEN BioTECH).

\section{Cell Proliferation and Colony Formation Assay}

Cell proliferation was measured using the $3-(4,5-$ dimethylthiazol-2-yl)-2, 5-diphenyltetrazolium bromide (MTT) (Solarbio) method in the different groups on days 1 through 5. Each experiment was performed in triplicate and repeated three times. For the colony formation assay, 200 cells per well were seeded in 6-well plates and cultured for 14 days in medium that contained $10 \%$ fetal bovine serum. The colonies were fixed with methyl alcohol for cell migration and invasion assays.

To assess cell migration, wound healing assays were performed. Transfected cells were cultured in 6-well plates until confluent monolayers were formed. A $200-\mu \mathrm{L}$ pipette tip was used to scratch the monolayer to create the wound. After the debris were washed away with phosphate-buffered saline, cells were cultured for 48 hours to allow wound healing. The cell invasion assay was performed using Transwell chambers $(8-\mu \mathrm{m}$ pore size; Millipore, Burlington, MA) with Matrigel (BD Biosciences). The detailed procedure was performed according to the manufacturer's instruction. The number of invaded cells was counted in five randomly selected microscopic fields and photographed.

\section{Xenograft Tumor Growth Analysis}

HCT116 cells stably infected with shControl or shMRPL35 were injected subcutaneously into the dorsal surface of each animal [6-week-old male nude mice obtained from the Animal Center of the Chinese Academy of Sciences (Shanghai, China); $n=3$ ]. Tumor size was measured at the indicated times using Vernier calipers. Tumors were excised after 21 days. The tumor tissues were formalin-fixed and paraffin-embedded for hematoxylin and eosin staining and IHC staining of Ki67. The NIH's Guide for the Care and Use of Laboratory Animals ${ }^{19}$ was followed for all animal experiments.

\section{Measurement of Mitochondrial Membrane Potential and ROS}

The mitochondrial membrane potential $(\Delta \Psi \mathrm{m})$ and ROS of cells were detected by flow cytometry and fluorescence microscopy according to the manufacturer's instructions (Cell Signaling Technology, KeyGEN BioTECH, Nanjing, China). Cells were untreated or treated with carbonyl cyanide 3-chlorophenylhydrazone ( $400 \mu \mathrm{mol} / \mathrm{L}, 20$ minutes), followed by labeling with tetramethylrhodamine ethyl ester 
(200 nmol/L, 30 minutes). For ROS assay, cells were incubated with dihydroethidium probe $(100 \mu \mathrm{mol} / \mathrm{L})$ for 1 hour, and fluorescence of the cells was examined and quantified with fluorescence microscopy (Olympus, Tokyo, Japan) and flow cytometry (FACSCalibur, BD Biosciences).

\section{Statistical Analysis}

The statistical software SPSS 19.0 (IBM, White Plains, NY) and GraphPad Prism 6 (GraphPad Software, San Diego, CA) were used to perform the statistical analyses. The data are generally expressed as the means $\pm \mathrm{SD}$. The $P$ values for the Kaplan-Meier survival analysis were generated by the log-rank test. $P<0.05$ was considered statistically significant, using $t$-test or one-way analysis of variance.

\section{Results}

MRPL35 mRNA and Protein Levels Are Highly Expressed in CRC Tissues and Cells

Analysis of The Cancer Genome Atlas (TCGA) data showed that MRPL35 was expressed differentially in tumor versus normal tissues, especially showing higher expression status in CRC tissue (Supplemental Figure S1A). To confirm this result, the expression of MRPL35 was compared in paired human CRC tissues by Western blot analysis and quantitative RT-PCR. CRC tissues displayed higher levels of MRPL35 protein than the paired adjacent normal tissues in $70 \%$ of cases (7 of 10) (Figure 1A). Consistent with elevated protein overexpression, MRPL35 mRNA was also overexpressed in $73.08 \%$ of CRC tissue samples (19 of 26) (Figure 1B). The expression of MRPL35 was next studied in CRC cells. MRPL35 was overexpressed in most CRC cells except for SW620 cells (Figure 1, C and D), in comparison with that in the normal mucosal epithelial cell, FHC.

IHC was used to confirm MRPL35 expression in the CRC tissues and matched cancer-adjacent tissues. MRPL35 was distributed mainly in the cytoplasm, and its expression was significantly up-regulated in CRC tissues (Figure 1E). Moreover, the patients with high expression of MRPL35 $(n=80)$ had shorter overall survival than patients with low expression of MRPL35 $(n=71 ; P<0.01)$ (Figure 1F), indicating that the level of MRPL35 expression was correlated with clinical outcome of CRC. Surprisingly, it was contrary to the result of survival analysis on TCGA (Supplemental Figure S1, B and C). The discrepancy may be attributed to differences in the sample population. Overall, elevated expression of MRPL35 correlated to CRC progression and may be a biomarker for early stage CRC.

\section{Down-Regulation of MRPL35 Attenuates CRC Cell Proliferation and Induces Apoptosis in Vitro}

To further examine the physiological role of MRPL35 in CRC progression, MRPL35 expression was down-regulated by infecting the CRC cell lines HCT116, LS174T, SW480, and HT29 with lentiviral particles expressing shMRPL35 or shControl (Supplemental Figure S2). The green fluorescence intensity represented the efficiency of infection, which was consistently $>80 \%$. On transfection, the expression of MRPL35 was significantly down-regulated in CRC cells (HCT116, LS174T, SW480, and HT29), indicated by RTqPCR and Western blot assays (Supplemental Figure S2, $\mathrm{B}$ and $\mathrm{C})$.

The effects of decreased MRPL35 expression were assessed on these cells. First, the effect on proliferation of the CRC cells was determined with the use of the MTT assay. Down-regulation of MRPL35 inhibited CRC cell proliferation by $62.3 \%$ in HCT116 cells, $65.5 \%$ in SW480 cells, 54.5\% in LS174T cells, and 62.2\% in HT29 cells (Figure 2A). Colony formation assays confirmed the above result, because down-regulation of MRPL35 reduced the number of colonies compared with the controls (Figure 2, B and C). Then, it was determined whether MRPL35 knockdown induced apoptosis in CRC cells. The percentage of apoptotic cells was lower in the control group than those infected with shMRPL35 in HCT116 cells $(5.31 \%$ versus 9.13\%), as well as in other CRC cells (3.63\% versus $9.33 \%$ in SW480 cells, $7.36 \%$ versus $19.52 \%$ in LS174T cells, and $6.99 \%$ versus $21.07 \%$ in HT29 cells) (Figure 2, D and E). However, down-regulation of MRPL35 did not significantly affect the migration and invasion of HCT116 cells (Supplemental Figure S3, A-D). Consistent with this result, proteins related to epithelial-mesenchymal transition, such as Vimentin, $\beta$-catenin, and matrix metallopeptidase 9 showed no significant changes (Supplemental Figure S3E). Epithelial-mesenchymal transition has been shown to play a critical role in cancer cell migration and invasion. ${ }^{20,21}$

\section{MRPL35 Knockdown Inhibits CRC Tumor Growth in Vivo}

Having demonstrated an effect of MRPL35 knock-down on CRC cell proliferation in vitro, the effect of MRPL35 knockdown was investigated on CRC cell growth in nude mice. HCT116 cells were selected for establishing the xenograft model. HCT116 cells have the most efficient infection by lentivirus. Besides, down-regulation of MRPL35 can significantly inhibit the proliferation of HCT116 cells. HCT116 cells stably infected with shMRPL35 lentivirus or shControl were injected subcutaneously into the dorsal surface of each nude mouse (Figure 3A). Compared with the control groups, MRPL35 knockdown significantly suppressed CRC growth in nude mice (Figure 3B). After 21 days, the tumor volumes of the shMRPL35 group were significantly smaller than those generated from the control group $(P<0.05)$ (Figure 3C).However, there was not much difference between the groups until day 7 , suggesting that there was no effect of MRPL35 during the initiation of tumor but only its progression. To determine whether the reduction in tumor growth was associated with an antiproliferative effect, immunohistochemical analysis for the proliferation marker 
A

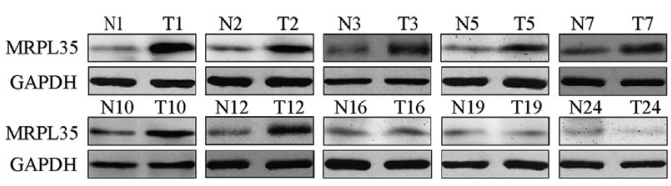

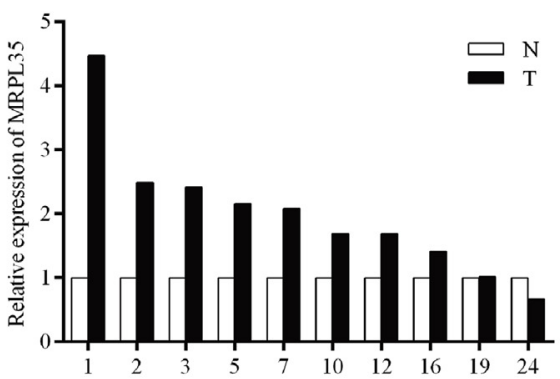

C

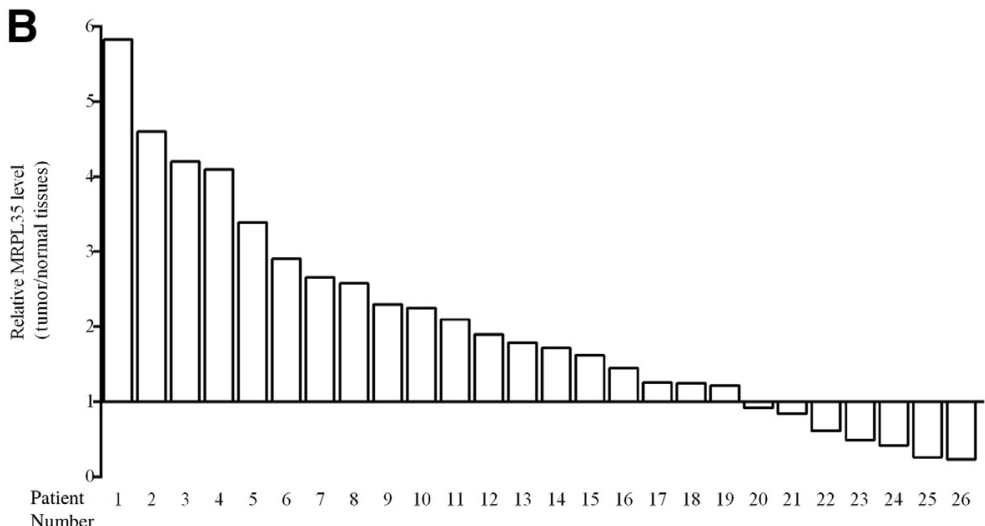

$\mathbf{E}$
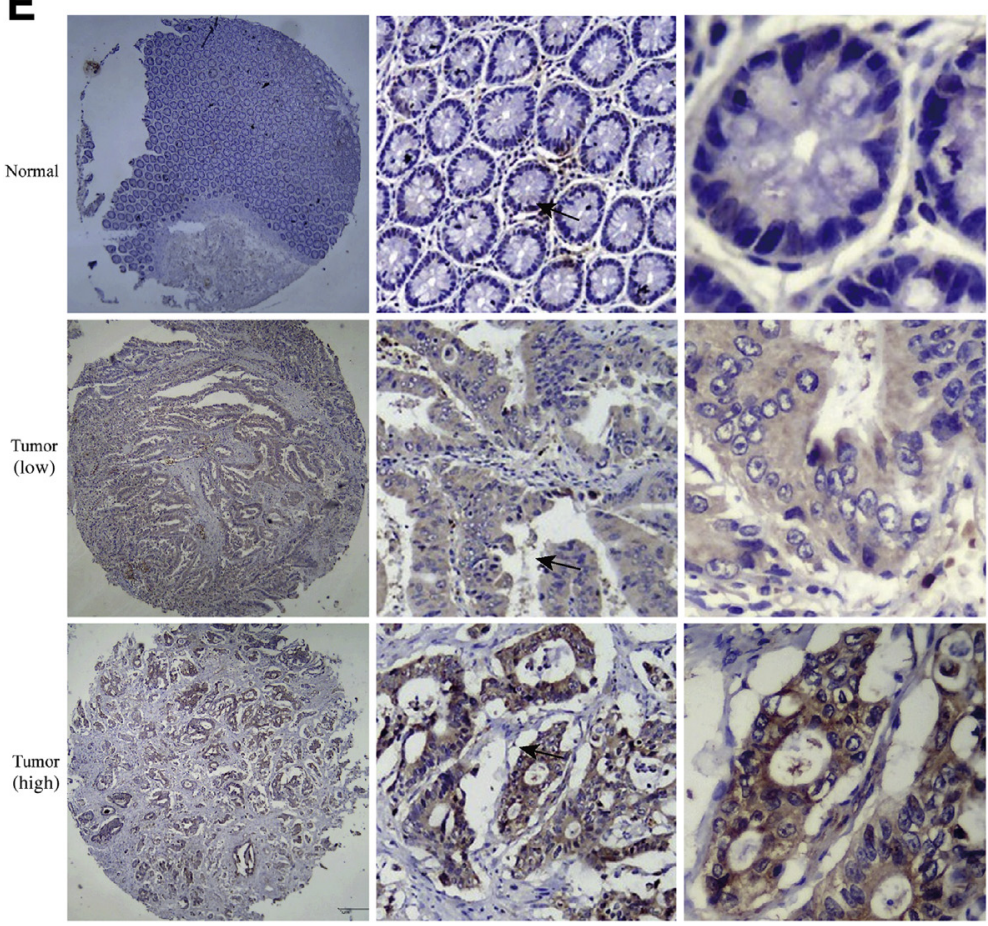

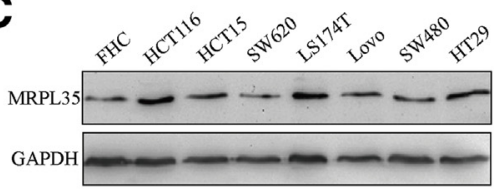

D

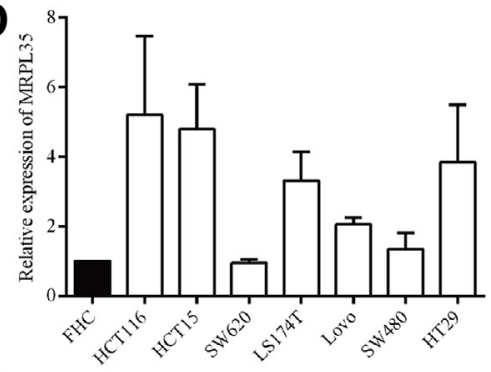

$\mathbf{F}$

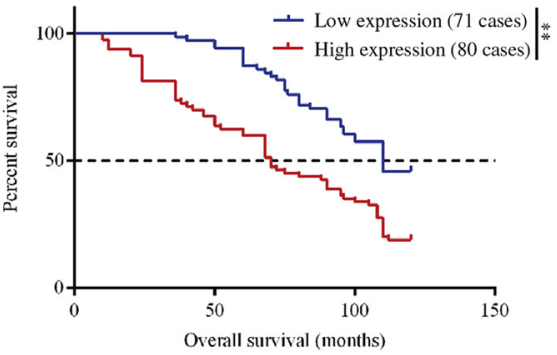

Figure 1 Mitochondrial ribosomal protein L35 (MRPL35) expression is up-regulated in colorectal cancer (CRC) patients and cell lines. A: Total proteins extracted from paired tissues of the CRC patients (selected on the basis of MRPL35 mRNA level) were analyzed by Western blot analysis with MRPL35-specific antibody. The protein levels were quantified by using ImageJ software version 1.50i (NIH, Bethesda MD). Glyceraldehyde-3-phosphate dehydrogenase (GAPDH) was used as a loading control. B: The mRNA levels of MRPL35 of CRC tissues were detected by quantitative RT-PCR (RT-qPCR). C and D: Western blot analysis and RT-qPCR analysis of the expression of MRPL35 in CRC cells (HCT116, HCT15, SW620, LS174T, Lovo, SW480, HT29) and normal mucosal epithelial cell FHC. E: Representative immunohistochemical staining detection of MRPL35, revealing higher staining in malignant CRC tissue than in paired cancer-adjacent normal tissue. The areas indicated by black arrows are shown in higher magnification to the right. F: Survival analysis of CRC patients based on MRPL35 expression by the Kaplan-Meier method. Dashed line indicates the median survival percent. Data are expressed as means \pm SD. $n=10$ paired tissues (A); $n=26$ CRC tissues (B); $n=3$ or more experiments (C and $\mathbf{D}) .{ }^{*} P<0.01$. Original magnification: $\times 40$ (E, left column); $\times 100(\mathbf{E}$, middle column); $\times 400(\mathbf{E}$, right column). GAPDH, glyceraldehyde-3-phosphate dehydrogenase; N, matched cancer-adjacent normal tissues; T, colorectal cancer tissues. 

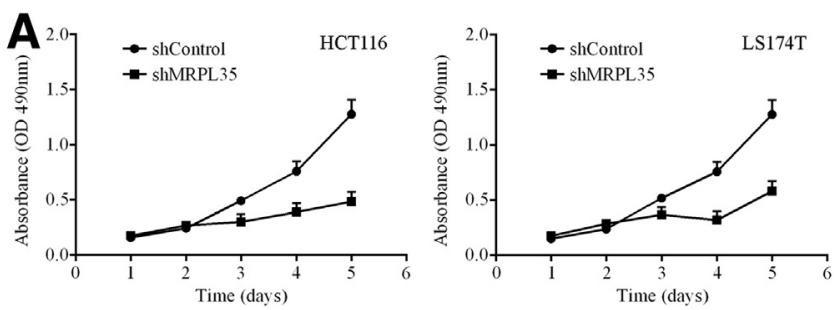

B нсти16

LS174T
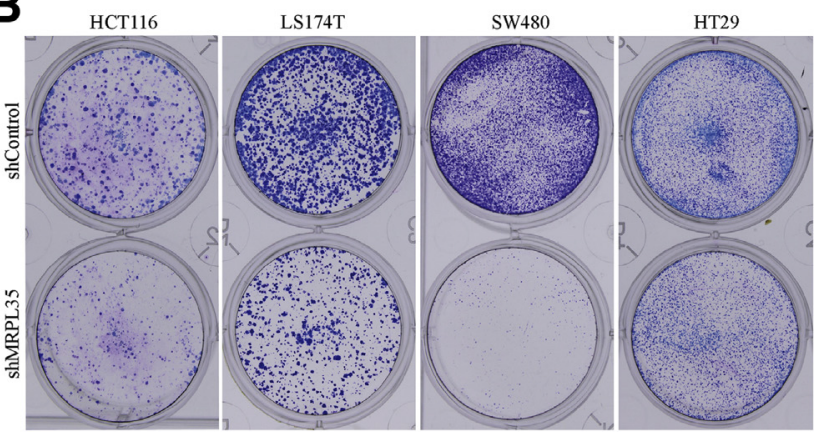

E
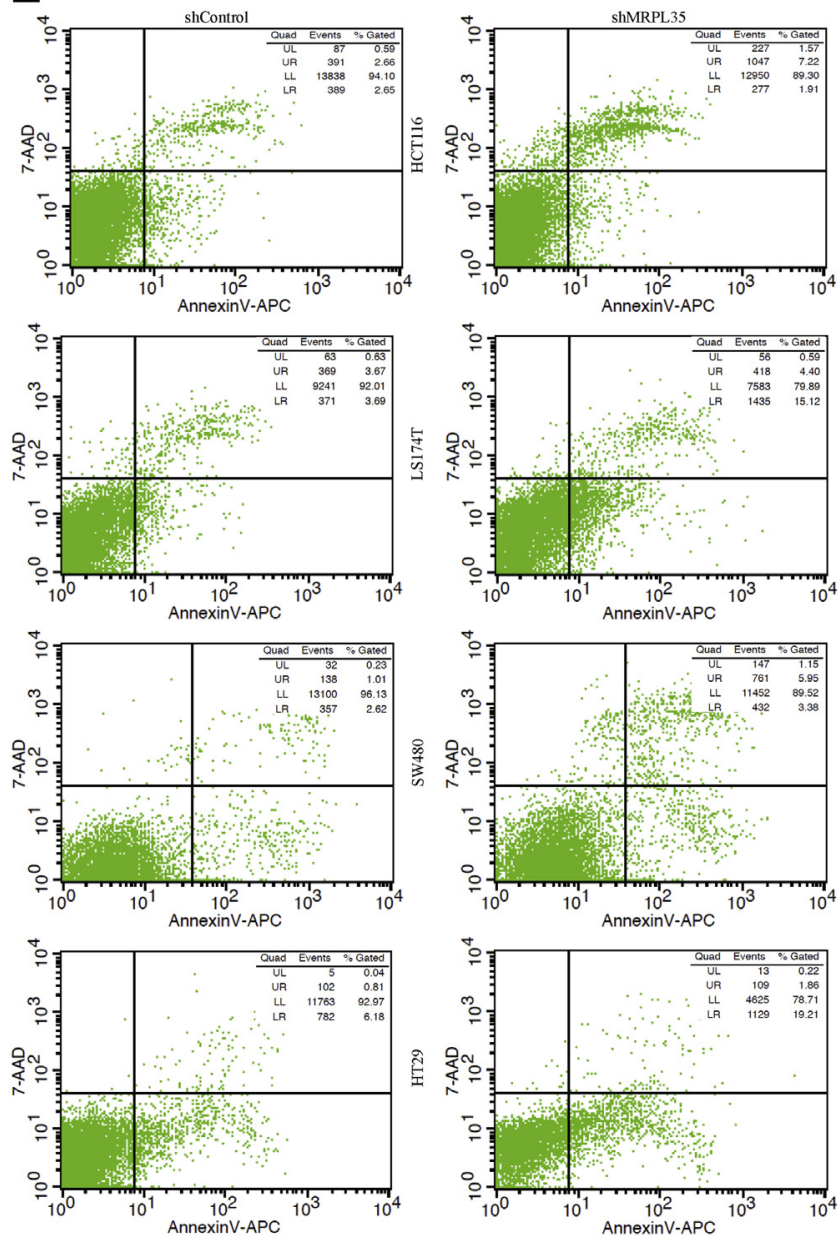

Ki-67 was performed on excised engrafted tumor tissues of each experimental group. A striking decrease in the number of nuclei positively stained for the Ki-67 protein was observed in the shMRPL35 group compared with the control group
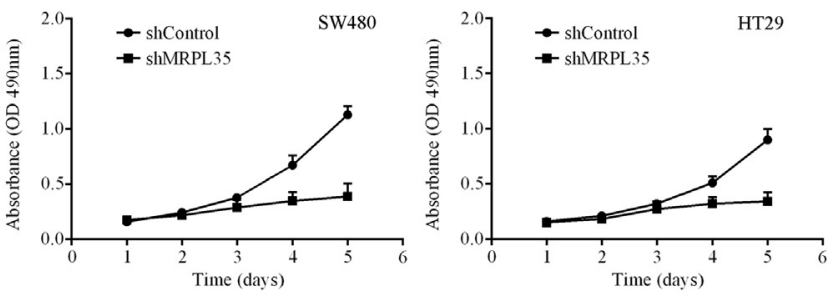

C

D
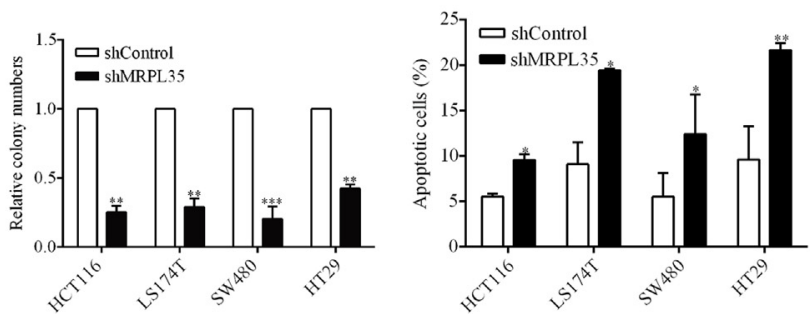

Figure 2 Down-regulation of mitochondrial ribosomal protein L35 (MRPL35) attenuated colorectal cancer (CRC) cell proliferation and induced apoptosis in vitro. A: Reduction of MPRL35 inhibited the growth rate of CRC cells (HCT116, LS174T, SW480, HT29) detected by 5-diphenyltetrazolium bromide (MTT) assay. B and C: Colony formation assays for CRC cells were infected as in A. D and E: Representative flow cytometric analysis of apoptosis stained with Annexin V-allophycocyanin (APC) and 7-aminoactinomycin D (7-AAD) in CRC cells infected with ShMRPL35 or shControl. Data are expressed as means \pm SD. $n=3$ independent experiments repeated three times with similar results. ${ }^{*} P<0.05,{ }^{* *} P<0.01$, and ${ }^{* *} P>0.001$ versus shControl. 

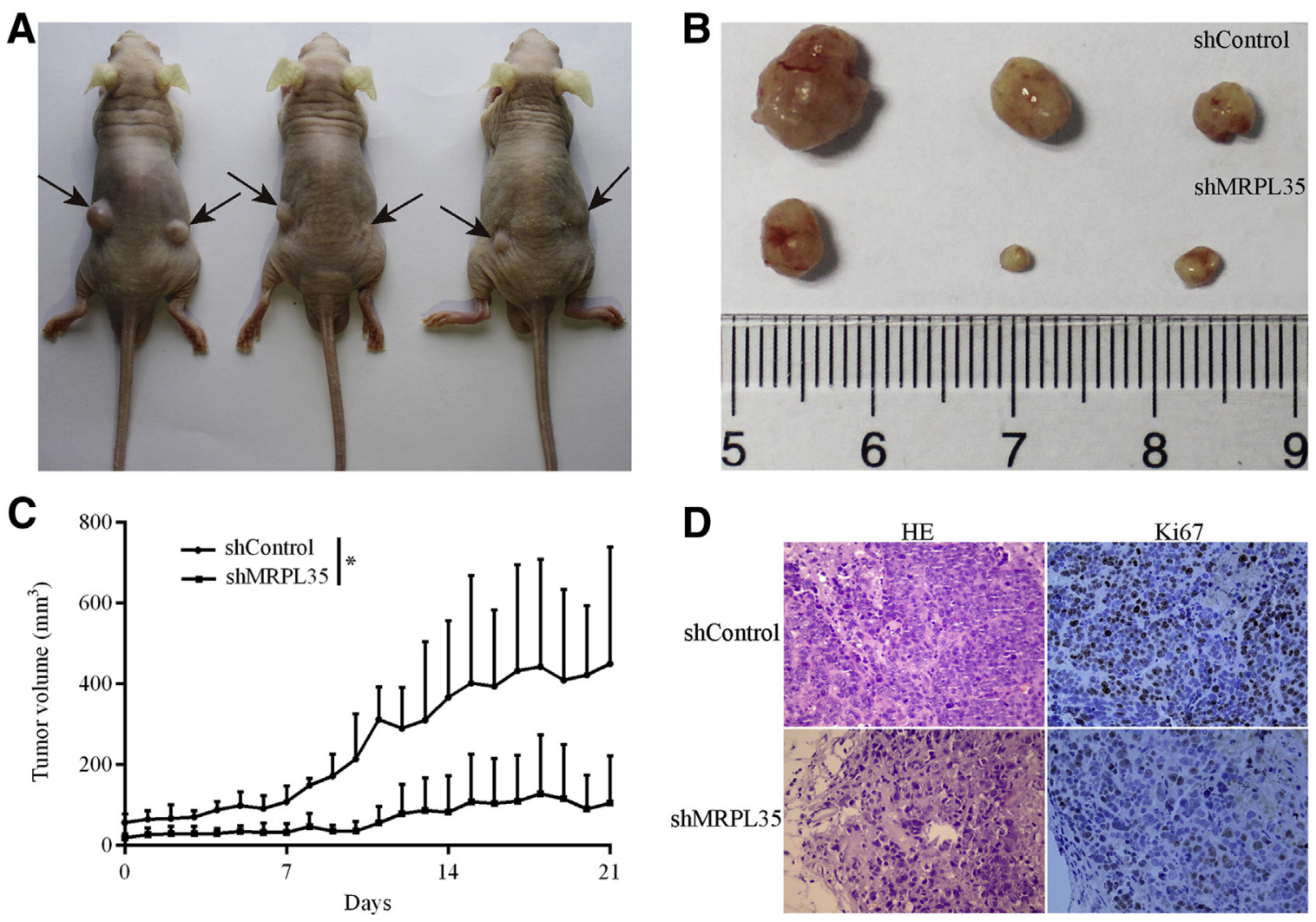

Figure 3 Knockdown of mitochondrial ribosomal protein L35 (MRPL35) suppressed colorectal cancer (CRC) cell growth in vivo. HCT116 cells stably transfected with shMRPL35 or shControl were injected subcutaneously into nude mice. The mice were euthanized, and the tumors were excised. A: Image of mice bearing shControl (left arrows) or shMRPL35 (right arrows). HCT116 cell xenografts at 21 days after injection. B: Excised tumors from shControl (upper) or shMRPL35 (lower) HCT116 cells. C: At the indicated times, tumors were measured with Vernier calipers. D: Representative hematoxylin and eosin (HE) staining of neoplasms and immunohistochemical staining of Ki67 in tumors. Data are expressed as means \pm SD. $n=3$. ${ }^{*} P<0.05$. Original magnification, $\times 40$ (D).

\section{MRPL35 Knockdown Induces ROS Leading to DNA Damage}

ROS are known to play a major role in the development of CRC, ${ }^{22-24}$ and excessive ROS could enter the nucleus to cause DNA damage. ${ }^{25-27}$ To determine whether ROS level played a role in the inhibition of proliferation caused by MRPL35 knockdown, it was examined whether MRPL35 knockdown affected intracellular ROS generation in CRC. Red fluorescence representing ROS production was significantly increased by two times after down-regulation of MRPL35 in HCT116 cells (Figure 4A). It was then tested whether generation of ROS resulted in DNA damage by measuring ATM S1981 phosphorylation as a DNA damage marker. ${ }^{28,29}$ ATM S1981 phosphorylation was increased (Figure 4D), accompanied by increased phosphorylation of H2A.X on Ser139 $(\gamma-\mathrm{H} 2 \mathrm{AX})$, another hallmark of DNA damage response ${ }^{30}$ (Figure 4D). Consistent with the abovementioned observations, overexpressing or rescuing MRPL35 expression by plasmid GV147/MRPL35 in HCT116 cells reduced the phosphorylation of ATM and H2A.X (Supplemental Figure S4, Figure 4E).

To further verify that the DNA damage caused by MRPL35 was mediated by increased production of ROS, it was tested whether the ROS scavenger NAC could decouple DNA damage from MRPL35 knockdown (Supplemental Figure S5A). Consistent with the hypothesis, NAC treatment abolished the induction of $\gamma-\mathrm{H} 2 \mathrm{AX}$ and ATM phosphorylation (Figure 4D), further demonstrating that induction of DNA damage was mediated by ROS. Dihydroethidium fluorescence intensity by flow cytometry further supported this conclusion (Figure 4, B and C, and Supplemental Figure S5, B and C). Overall, these data demonstrated that MRPL35 knockdown could induce ROS accumulation to cause DNA damage.

\section{DNA Damage Arrests the Cell Cycle at the $G_{2} / M$ Phase}

Cell-cycle checkpoints are downstream effectors in response to DNA damage, which can cause cell cycle arrest at the $\mathrm{G}_{1}$ or $\mathrm{G}_{2}$ phase. Because MRPL35 knockdown resulted in DNA damage, it was next determined how the cell cycle was affected. After treatment with shMRPL35 or shControl, DNA content in CRC cells was measured by FACS. SW480 cells pretreated with MRPL35 down-regulation displayed a clearly increased $\mathrm{G}_{2} / \mathrm{M}$ phase population (17.4\%) compared with the control cells $(7.8 \%)$ (Figure 5A) $(P<0.05)$. The same pattern was observed in HT29 cells (14.7\% versus 

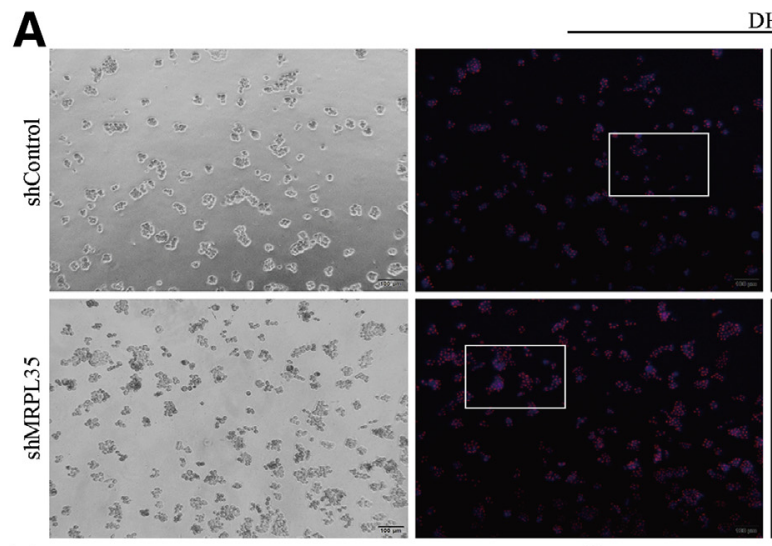

DHE

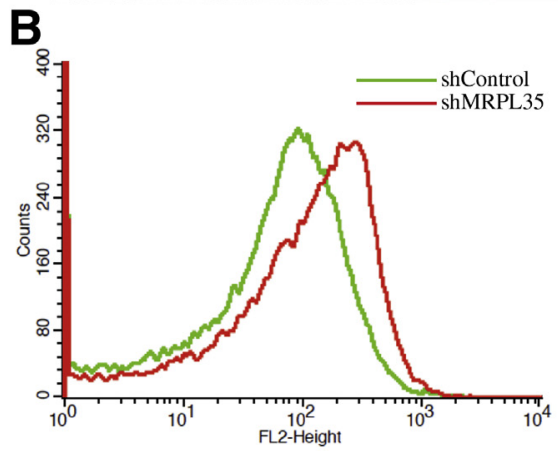

C
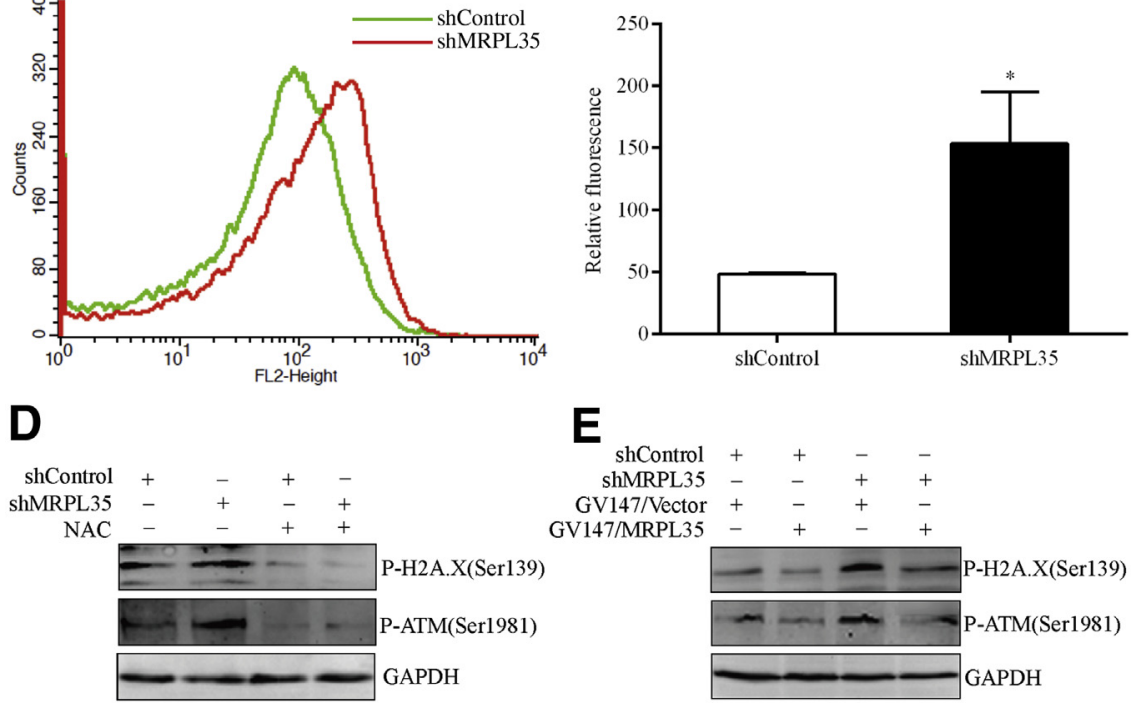

E

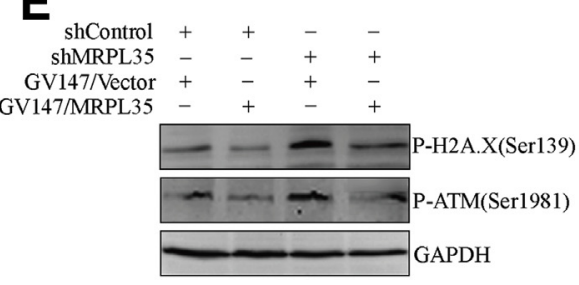

Figure 4 Mitochondrial ribosomal protein L35 (MRPL35) knockdown induced reactive oxygen species (ROS) and resulted in DNA damage. A: Detection of ROS by incubation with $100 \mu \mathrm{mol} / \mathrm{L}$ dihydroethidium (DHE) in both shMRPL35 and shControl groups in HCT116 cells. Cells were observed using a fluorescence microscope. Boxed areas are shown at higher magnification in the right column. B: HCT116 cells were treated as in A and analyzed by flow cytometry. The $x$ axis represents the red fluorescence intensity, the vertical axis represents cells analyzed by flow cytometry. C: Quantifications of relative mean red fluorescence intensity of shMRPL35 and shControl groups in HCT116 cells. D: Western blot analysis of P-H2A.X (Ser139) and $\mathrm{P}$-ataxia-telangiectasia mutated (ATM; Ser1981) protein levels in HCT116 cells infected with shMRPL35 or shControl, and with or without $10 \mathrm{mmol} / \mathrm{L}$ antioxidant $\mathrm{N}$-acetyl cysteine (NAC). E: Western blot analysis of P-H2A.X (Ser139) and P-ATM (Ser1981) protein levels in HCT116 cells infected with shMRPL35 or shControl and transfected with GV147/MRPL35 or GV147/Vector. $n=3$ independent experiments performed with similar results. ${ }^{*} P<0.05$ versus shControl. Scale bars $=100 \mu \mathrm{m}$. Original magnification: $\times 100(\mathbf{A}$, left and middle columns); $\times 400$ (A, right column).
9.3\%) and HCT116 cells (12.4\% versus 9.2\%). Although there was no statistically significant difference in HT29 and HCT116 cells, the cell cycle retardation could still be seen after MRPL35 down-regulation. The cell lines may have different reaction time on MRPL35 knockdown. In this experiment, all three cell lines were collected at the same time point for the sake of consistency.

DNA damage accumulation induced ATM phosphorylation and activation (Figure 4D). On ATM activation, downstream effectors, such as Chk2 and p53, were phosphorylated and activated, ${ }^{31,32}$ which in turn prevented the activation of the mitotic cyclin-dependent kinase (CDK)1cyclinB complex by blocking the dephosphorylation of threonine 14 /tyrosine $15 \mathrm{CDK} 1 .^{33,34}$ Consequently, the cell goes to $G_{2}$ arrest. To investigate if this pathway was activated by MRPL35 knockdown, the Western blot assay was used to examine the expression level and phosphorylation status of key regulators of the $\mathrm{G}_{2} / \mathrm{M}$ checkpoint, including Cdk1/cdc2, cyclin B1, p21 Waf1/Cip1, Wee1, Chk2, and p53 in MRPL35 knockdown and control cells. ${ }^{35,36}$ Significant increases in p53 phosphorylation at Ser15 and Chk2 phosphorylation at Thr68 (Figure 5B) were observed after down-regulation of MRPL35 in HCT116 cells. Similarly, MRPL35 knockdown significantly increased expressions of p21 and cdc2 phosphorylation at Tyr15 and decreased the expression of cyclin B1 (Figure 5B). DNA damage is known to cause the phosphorylation and activation of Wee1, which leads to the inhibition of Cdk1 and cell cycle arrest at the $\mathrm{G}_{2}$ phase. $^{37,38}$ HCT116 cells with low expression of MRPL35 showed that the phosphorylation of Wee1 was indeed elevated (Figure 5B). These results suggested that the ATM-Chk2/P53-Cdk1/cyclin B1 cascade was involved in the $G_{2} / M$ arrest in response to MRPL35 knockdown.

DNA damage in response to MRPL35 knockdown was mediated by the increased production of ROS (Figure 4D). This conclusion would predict that the activation of the ATM-Chk2/P53-Cdk1/cyclin B1 cascade should also be dependent on the overproduction of ROS. This was indeed true as treatment with ROS scavenger NAC inhibited ATM, P53, and Chk2 (Figure 5B). These experiments together demonstrated that MRPL35 down-regulation resulted in 

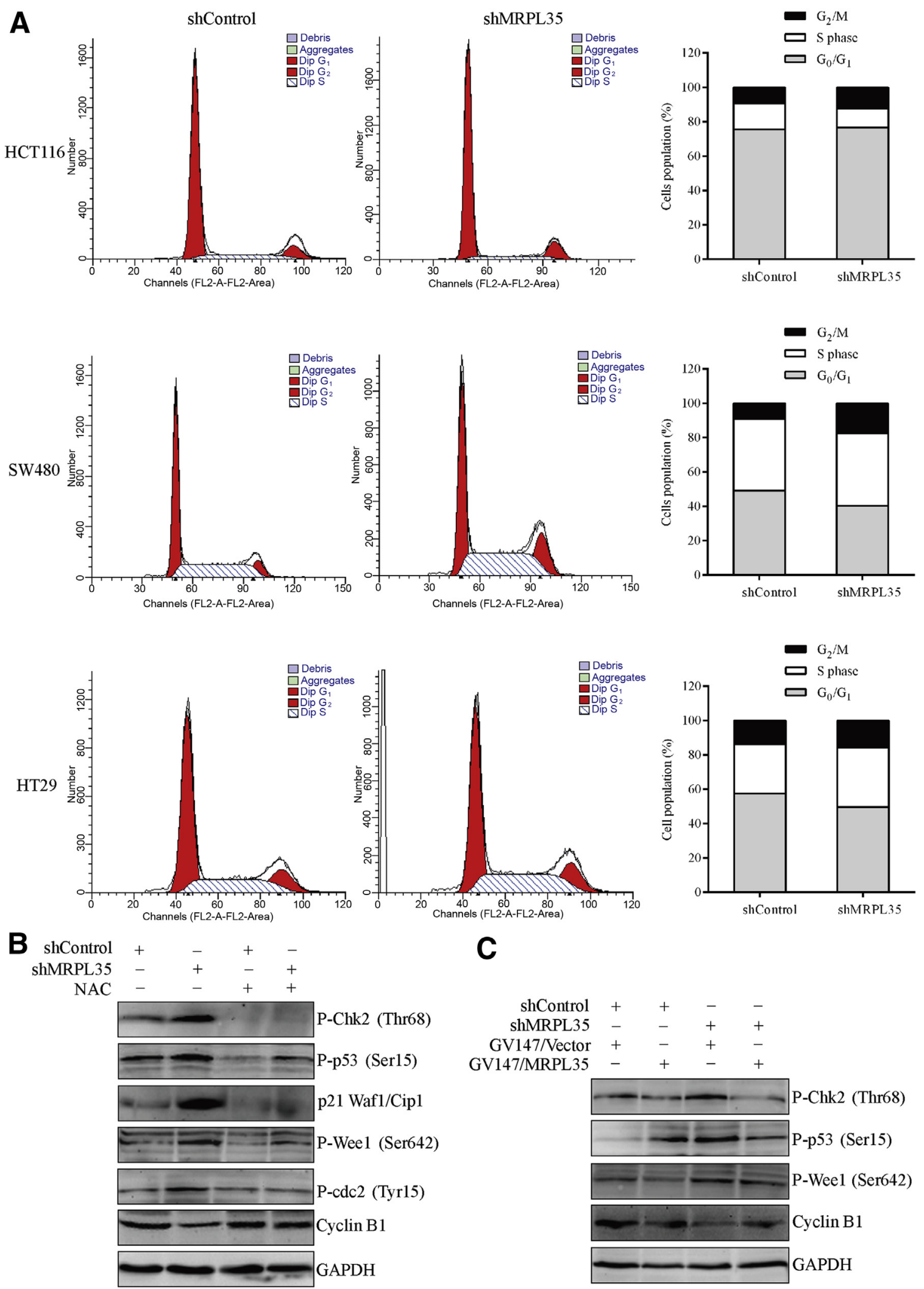

Figure 5 Mitochondrial ribosomal protein L35 (MRPL35) knockdown caused $\mathrm{G}_{2} /$ M phase arrest in colorectal cancer (CRC) cells. A: Flow cytometric analysis of the cell cycle in HCT116 cells when MRPL35 was down-regulated. Representative fluorescence histograms show the effect on the cell cycle distribution of HCT116, SW480, and HT29 cells. Bar graphs show the percentage of CRC cells in $G_{0} / G_{1}, S$, and $G_{2} / M$ phases. B and C: Representative Western blot analyses for p-Chk2, P-p53, p21 Waf1/Cip1, P-Wee1, P-cdc2, and cyclin B1 proteins in MRPL35 knockdown of HCT116 cells. Data are expressed as the means \pm SD. $n=3$ independent experiments. GAPDH, glyceraldehyde-3-phosphate dehydrogenase. 
A
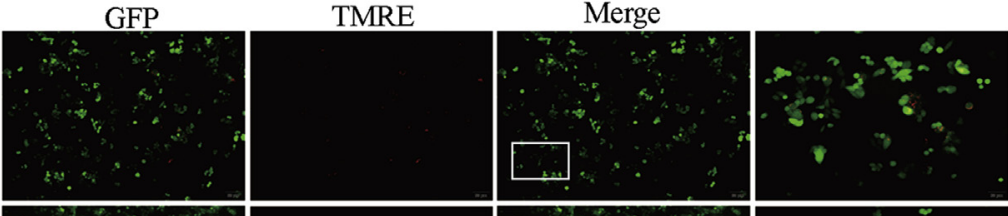

ShMRPL35+CCCP
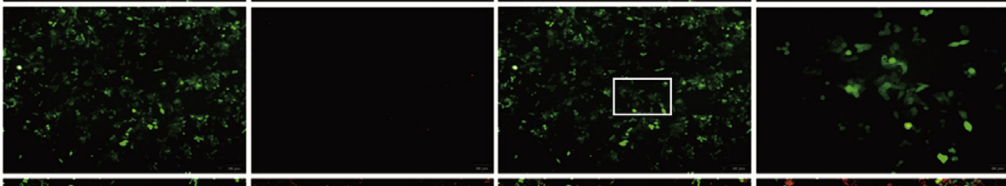

shControl
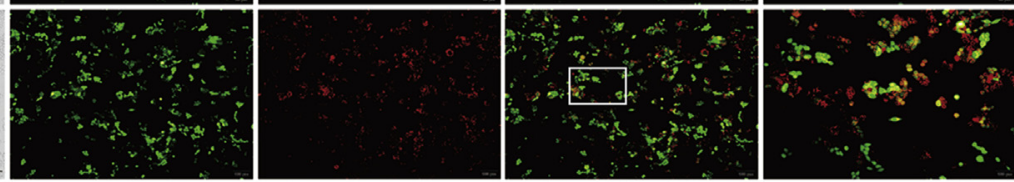

ShMRPL35
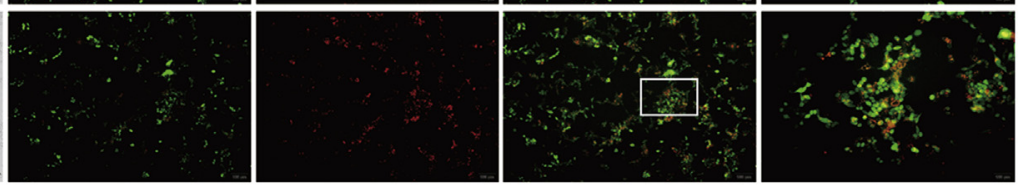

B

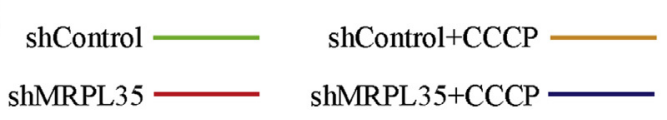

C
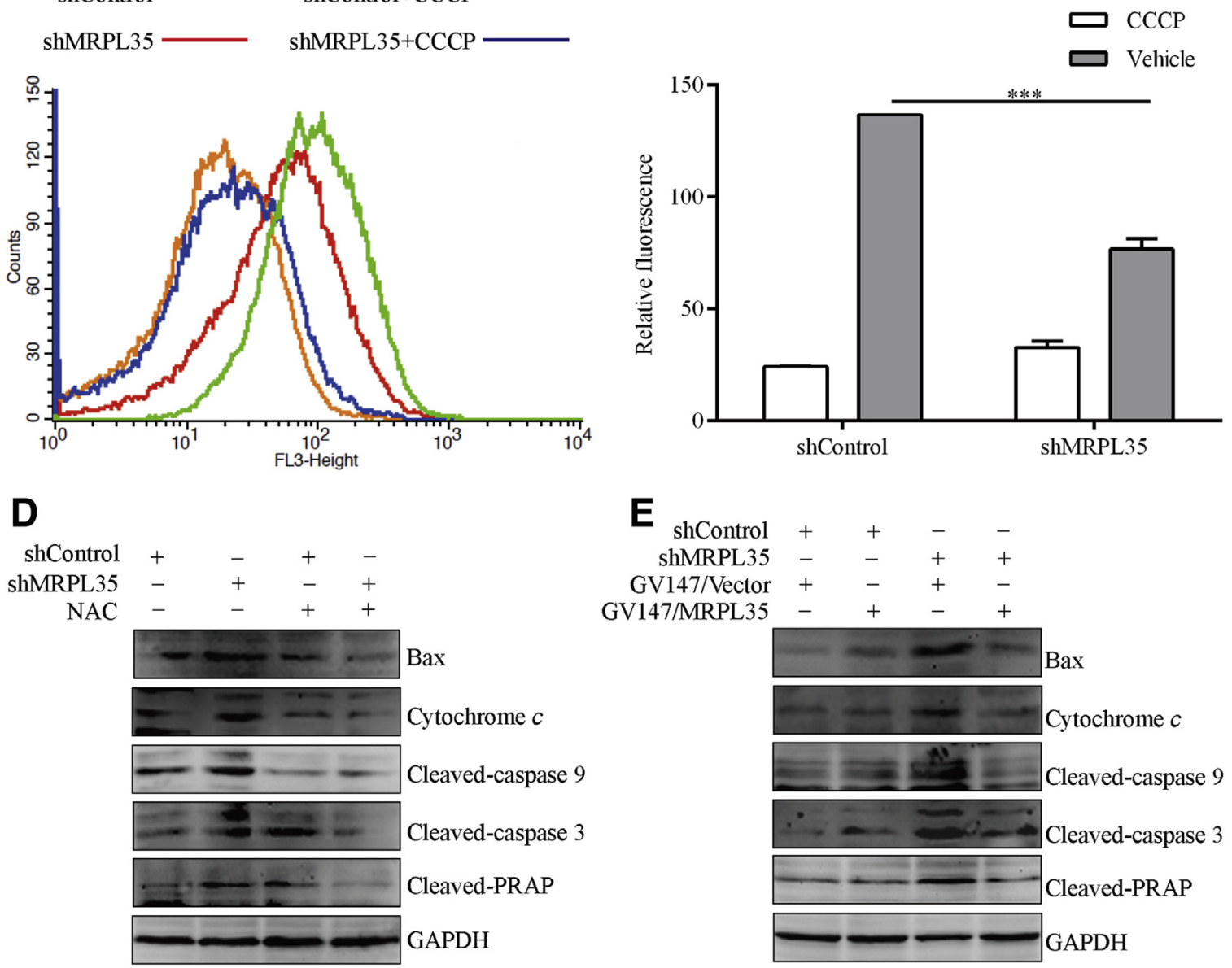

Figure 6 Reactive oxygen species (ROS) decreased mitochondrial membrane potential $(\Delta \Psi \mathrm{m})$ to induce HCT116 cell apoptosis. A: Detection of $\Delta \Psi \mathrm{m}$ by incubation with $200 \mathrm{nmol} / \mathrm{L}$ tetramethylrhodamine ethyl ester perchlorate (TMRE) in mitochondrial ribosome protein L35 (MRPL35) knockdown of HCT116 cells with or without $400 \mu \mathrm{mol} / \mathrm{L}$ mitochondrial membrane disrupter carbonyl cyanide 3-chlorophenylhydrazone (CCCP). Cells were observed using a fluorescence microscope. Boxed areas are shown at higher magnification in the right column. B and C: HCT116 cells treated as in A were analyzed by flow cytometry, and quantification of relative mean red fluorescence intensity was analyzed. D and E: Representative Western blot analyses for Bcl-1-associated X protein (Bax), cytochrome $c$, cleaved-caspase 9, cleaved-caspase 3, and cleaved-proline-rich acidic protein 1 (PRAP) proteins in MRPL35 knockdown of HCT116 cells. Data are expressed as means \pm SD. $n=3$ independent experiments. ${ }^{* *} P<0.001$. Scale bars $=100 \mu \mathrm{m}$. Original magnification: $\times 100$ (A, middle three columns); $\times 400$ (A, right column). GAPDH, glyceraldehyde-3-phosphate dehydrogenase; GFP, green fluorescent protein; NAC, $N$-acetyl cysteine. 


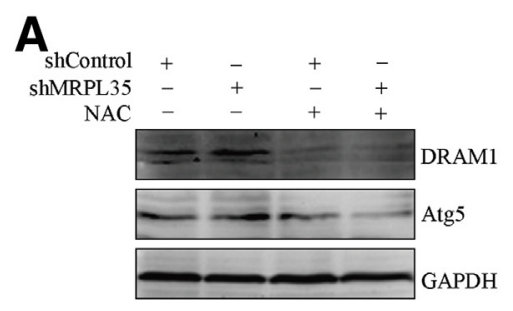

C

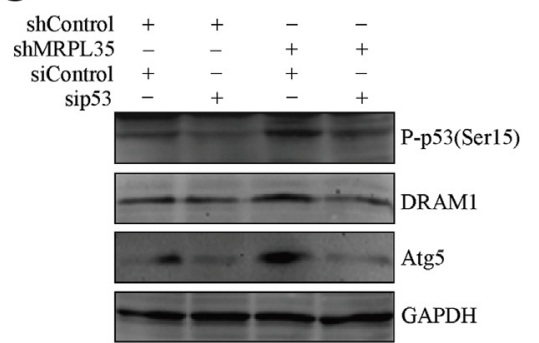

E
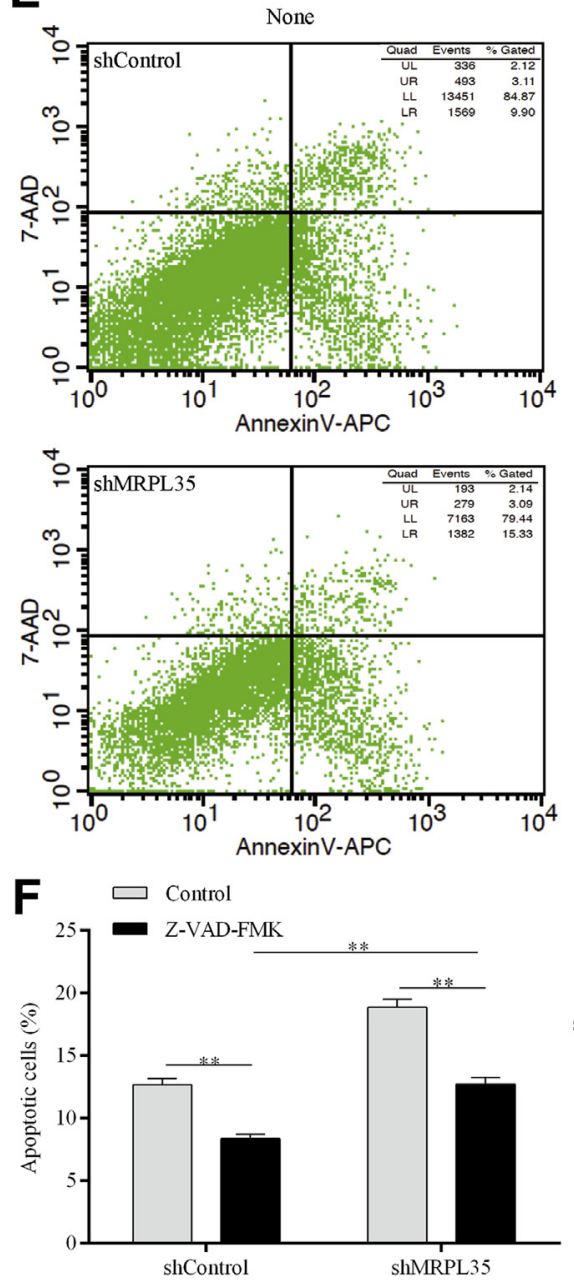

B

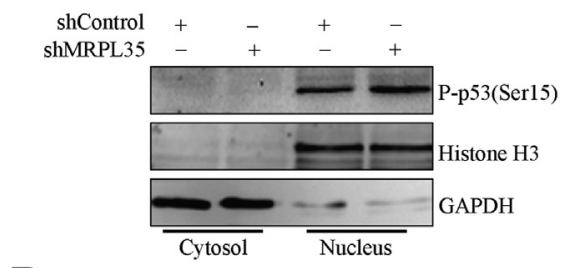

D
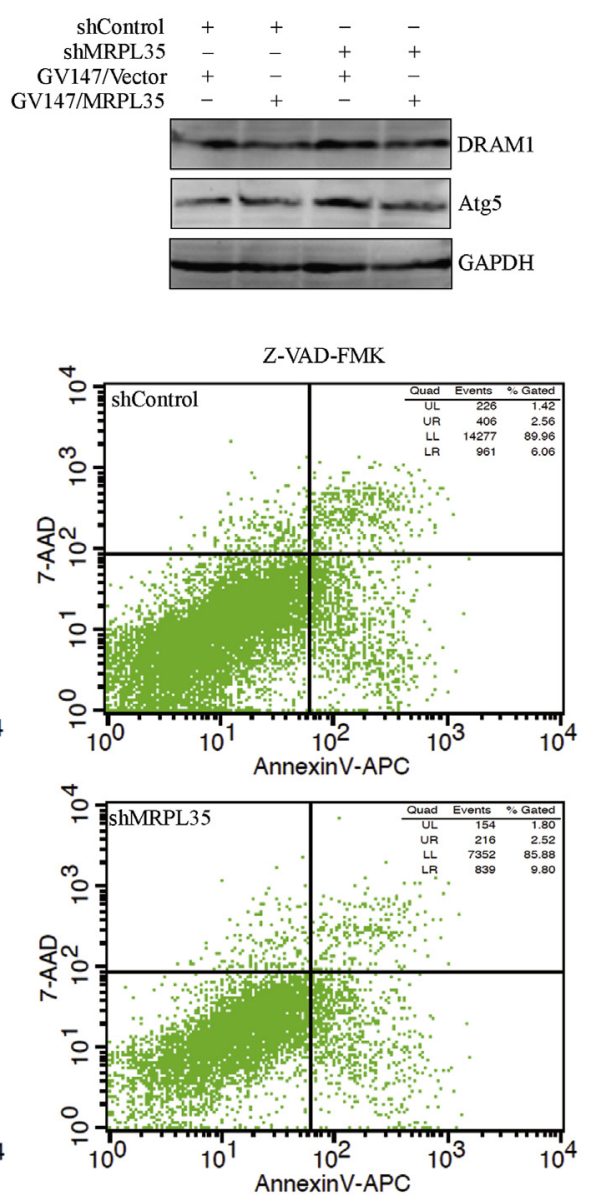

$\mathbf{G}$

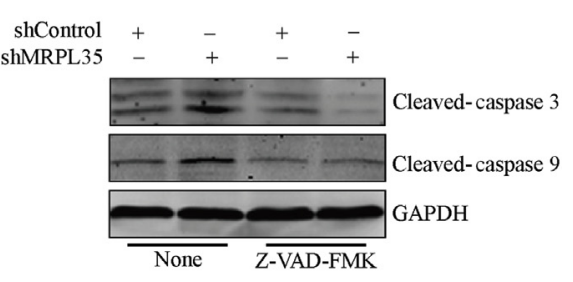

Figure 7 DNA damage and p53-induced autophagy. A: HCT116 cells in which mitochondrial ribosomal protein L35 (MRPL35) was knocked down were treated with and without $10 \mathrm{mmol} / \mathrm{L}$ antioxidant $\mathrm{N}$-acetyl cysteine (NAC) and analyzed by Western blot analysis. B: HCT116 cells, in which MRPL35 was down-regulated, were fractionated into nuclear and cytosolic extracts and analyzed by Western blot analysis. Histone $\mathrm{H} 3$ and glyceraldehyde-3-phosphate dehydrogenase (GAPDH) were both used as controls. C: HCT116 cells were transfected with sip53 or siControl and analyzed by Western blot analysis. D: HCT116 cells were transfected with GV147/MRPL35 or GV147/Vector and analyzed by Western blot analysis. E and F: HCT116 cells were treated with and without 20 $\mu \mathrm{mol} / \mathrm{L}$ pan-caspase inhibitor Z-VAD-FMK. Cells stained with Annexin V-allophycocyanin (APC) and 7-aminoactinomycin $D(7-A A D)$ were analyzed for viability by representative flow cytometry. G: Western blot analysis of cleaved-caspase3 and cleaved-caspase9 in HCT116 cells after shControl and ShMRPL35 infection and with or without ZVAD-FMK. GAPDH was used as a loading control. Data are expressed as means \pm SD of percentage of cells in various phases of the process. $n=3$ or more independent experiments. ${ }^{* *} P<0.01$. DRAM1, DNA damage regulated autophagy modulator 1 .
ROS accumulation, which led to DNA damage and $\mathrm{G}_{2} / \mathrm{M}$ arrest. To further confirm this conclusion, it was tested if the overexpression of MRPL35 could rescue the cell cycle arrest caused by MRPL35 knockdown. MRPL35 was first knocked down with shMRPL35 in HCT116 cells, and then the expression of MRPL35 was restored using plasmid GV147/MRPL35. The normal cell cycle was recovered (Figure 5C). These results collectively showed that $\mathrm{G}_{2} / \mathrm{M}$ phase cell cycle arrest was caused by DNA damage induced by MRPL35 knockdown. 


\section{ROS Induces CRC Apoptosis by Decreasing $\Delta \Psi \mathrm{m}$}

Excessive ROS can also affect $\Delta \Psi \mathrm{m}$ and damage mitochondria, which then leads to cellular apoptosis. ${ }^{39,40}$ Downregulation of MRPL35 significantly increased CRC cell apoptosis (Figure 2D).

The molecular mechanisms of apoptosis were further explored in HCT116 cells because of MRPL35 knockdown. To confirm the ROS involvement, both groups of HCT116 cells were first exposed to $400 \mu \mathrm{mol} / \mathrm{L}$ mitochondrial membrane disrupter, carbonyl cyanide 3chlorophenylhydrazone, and then treated with or without $10 \mathrm{mmol} / \mathrm{L}$ NAC. The cells were then incubated with 200 $\mathrm{nmol} / \mathrm{L}$ tetramethylrhodamine ethyl ester perchlorate, and $\Delta \Psi \mathrm{m}$ was measured by flow cytometry (Figure $6, \mathrm{~A}$ and B). The mitochondrial membrane integrity, indicated by the $\Delta \Psi \mathrm{m}$, was disrupted in the MRPL35 knockdown group, and pretreatment with NAC attenuated the decrease in $\Delta \Psi \mathrm{m}$ (Figure 6, A-C, and Supplemental Figure S6), indicating that ROS was a link between MRPL35 knockdown and the decrease in $\Delta \Psi \mathrm{m}$. The mechanism of MRPL35 down-regulation-induced apoptosis was further explored. The proteins related to apoptosis were measured by Western blot analysis. Down-regulation of MRPL35 enhanced the expression of Bax, stimulated the release of cytochrome $c$, and activated caspase-9 and caspase-3 (Figure 6D). Activated caspase- 3 could cause proteolytic cleavage of PARP, a key characteristic of apoptosis. ${ }^{41}$ Indeed, a proteolytic cleavage of PARP to an 89-kDa fragment (Figure 6D) was also increased in MRPL35 knockdown cells. Activation of both caspases 3 and 9, cytochrome $c$, and PARP by MRPL35 knockdown revealed the induction of apoptosis via a mitochondrial-dependent mechanism in HCT116 cells. In reverse, when ROS production was blocked by NAC or the expression of MRPL35 was rescued or overexpressed, all of the observed changes to the above proteins were reversed (Figure 6, D and E). These results further demonstrated that MRPL35 knockdown induced ROS accumulation, caused a loss of $\Delta \Psi \mathrm{m}$, and resulted in apoptosis in HCT116 cells.

DNA Damage and P53 Induce Autophagy in a DRAMDependent Manner

Results in the previous sections indicated that excessive ROS production resulted in DNA damage and a decrease in the $\Delta \Psi \mathrm{m}$, which then led to apoptosis. It has been reported that these events could also induce autophagy. ${ }^{40,42}$ To determine whether ROS-induced DNA damage resulted in autophagy, the expression of the damage-regulated autophagy modulator, DRAM1, was examined by Western blot analysis. DRAM1 expression was dramatically increased in HCT116 cells when MRPL35 was down-regulated (Figure 7A), and its expression was restored in the presence of NAC (Figure 7A). Consistent with this result, higher expression of ATG5 (Figure 7A), an effector of autophagy required for responses to all autophagic stimuli, ${ }^{43}$ was also detected. DRAM1 is a sensor, signaling autophagy in certain situations perhaps to target selective autophagic cargos. ${ }^{44}$ These results confirmed that autophagy was induced by MRPL35 knockdown.

A number of studies indicated that p53 plays dual roles in the regulation of autophagy. ${ }^{45}$ Nuclear p53 was shown to promote autophagy by transcriptionally regulating genes in the autophagic pathway, such as AMPK- $\beta 1 / 2$, phosphatase, and tensin homolog and DRAM, ${ }^{46,47}$ whereas cytoplasmic p53 inhibited autophagy. ${ }^{45}$ To establish whether p53mediated DRAM1 induced autophagy, the nuclear localization of p53 was characterized in response to MRPL35 knockdown. P53 was located in the nucleus, and it showed increased accumulation in MRPL35 knockdown of HCT116 cells compared with the control group (Figure 7B). MRPL35 knockdown of HCT116 cells were then transfected with sip53 or siControl to knockdown p53 protein levels. Inhibition of p53 expression resulted in attenuation

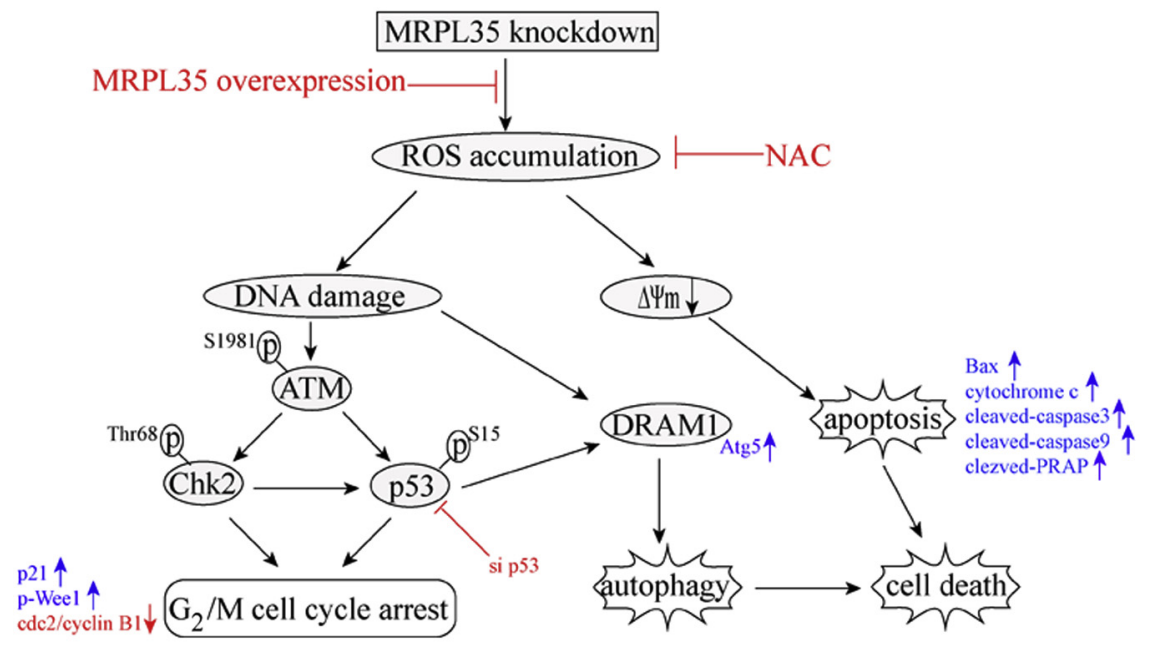

Figure 8 Proposed model of the mechanisms of mitochondrial ribosomal protein L35 (MRPL35) down-regulation-induced reactive oxygen species (ROS)-mediated DNA damage, which induced $\mathrm{G}_{2} / \mathrm{M}$ arrest and cell death of colorectal cancer (CRC) cells. Bars indicate inhibition, and arrows indicate activation. ATM, ataxia-telangiectasia mutated; DRAM1, DNA damage regulated autophagy modulator 1 ; NAC, $\mathrm{N}$-acetyl cysteine; PRAP, proline-rich acidic protein $1 ; \Delta \Psi \mathrm{m}$, mitochondrial membrane potential. 
of the expression of DRAM1 and Atg5 (Figure 7C), and we observed similar DRAM1 and Atg5 expression signature in MPRL35-rescued cells (Figure 7D). These results indicated that DRAM1 was induced by DNA damage via endogenous p53.

To gain mechanistic insights into autophagy in cell death, it was next determined whether autophagy caused by MRPL35 knockdown in HCT116 cells was sensitive to the pan-caspase inhibitor Z-VAD-FMK by flow cytometry. Although Z-VAD-FMK dramatically blocked the cleavage of caspase-3 and caspase- 9 (Figure $7 \mathrm{G}$ ), it failed to block the cell death induced by DRAM1 (Figure 7, E and F), indicating that the cell death due to MRPL35 knockdown was not mediated by a caspase-3- and caspase-9-dependent apoptosis. These results indicated that down-regulation of MRPL35 activated an autophagy-dependent cell death pathway that did not strictly rely on caspase activity for cell death execution.

\section{Discussion}

The development of CRC, like many other cancers, is a multistep process based on the accumulation of genetic and epigenetic alterations. ${ }^{48}$ Mitochondria are important mediators of tumorigenesis, but the relationship between mitochondria and tumorigenesis is still poorly understood. ${ }^{49,50}$ MRPs encoded by nuclear genes are important for mitochondrial-encoded protein synthesis and mitochondrial function. In addition to this primary function, MRPs may be directly involved in the process of cancer cell proliferation, apoptosis, and metastasis. ${ }^{12,51}$ Overexpression of MRPL41 contributes to p53 stability and induces apoptosis and causes cell cycle arrest at the $\mathrm{G}_{1}$ phase. ${ }^{14}$ MRPS36 overexpression is also found to delay cell cycle progression and to retard cell proliferation in association with $\mathrm{p} 53$ modification and $\mathrm{p} 21^{\mathrm{WAF} 1 / \mathrm{CIP} 1}$ expression. ${ }^{16}$ However, the function of most MRPs has not been investigated individually.

This study demonstrates that MRPL35 is up-regulated during progression of CRC, which is associated with poor prognosis for CRC patients. However, TCGA data indicate that the CRC patients with low expression of MRPL35 had shorter overall survival. The discrepancy may be attributed to differences in the population, ethnic and geographic, from which the samples are obtained. Clinical samples from other cities of China need to be selected for further validation. At the same time, the clinical sample size must be expanded to get more convincing data support. Knockdown of MRPL35 decreased the proliferation of colorectal carcinoma in vitro and in vivo, but it had no effect on migration or invasion. In addition, MRPL35 may only play a major role in the development of CRC rather than the stage of cancer initiation. MRPL35 knockdown induced ROS accumulation, which caused DNA damage and cell cycle arrest at the $\mathrm{G}_{2} /$ $\mathrm{M}$ phase, disrupted the $\Delta \Psi \mathrm{m}$ to induce apoptosis, and activated the autophagy-dependent cell death pathway (Figure 8).

It has been suggested that ROS such as superoxide, hydrogen peroxide, and hydroxyl radical, may have a causative role in the progression of carcinogenesis. ${ }^{52,53}$ Under physiological conditions, ROS are constantly generated in the mitochondria through the respiratory chain. ${ }^{53} \mathrm{At}$ normal cellular levels, ROS plays a role in normal cell signaling in the cell. However, when in excess, ROS may cause lipid, protein, and DNA damage and result in cell apoptosis. ${ }^{54}$

The data indicated that MRPL35 knockdown induced the generation of ROS, which then resulted in DNA damage. In response to the DNA damage, the phosphorylation of H2A.X on Ser139 ( $\gamma$-H2A.X) and ATM on Ser1981 increased, and the ATM-Chk2/P53-Cdk1/cyclin B1 cascade was activated, ultimately resulting in $\mathrm{G}_{2} / \mathrm{M}$ checkpoint arrest. The protein kinase ATM is best known for its role as a primary mediator of the DNA damage response. ${ }^{55} \mathrm{H} 2 \mathrm{~A} . \mathrm{X}$ is phosphorylated by ATM immediately after DNA damage. ${ }^{30,56}$ Although this DNA damage response pathway is well established, these data for the first time established that MRPL35 knockdown can cause overproduction of ROS to initiate the activation of this pathway.

As a protein kinase, ATM can also phosphorylate numerous proteins involved in cell cycle regulation and DNA repair, including p53, NBS1, 53BP1, BRCA1, Smc1, and Chk2. ${ }^{57,58}$ Chk2 was phosphorylated on Thr68, and p53 was phosphorylated at Ser15 by ATM. Their phosphorylation by ATM causes cell-cycle arrest at $\mathrm{G}_{1} / \mathrm{S}$, intraS, and $\mathrm{G}_{2} / \mathrm{M}$ checkpoints. Cell cycle progression is partly controlled by CDKs and their activating partners, the cyclins. ${ }^{59}$ The activation of $\mathrm{Cdk} 1$ kinase needs its interacting protein cyclin $\mathrm{B}$ to form the maturation-promoting factor, which phosphorylates their respective substrates and controls their functions. ${ }^{60}$ The p53 protein is a key tumor suppressor which plays a pivotal role in anticancer defense. ${ }^{61}$ Under normal conditions, p53 is kept at low levels through ubiquitination and proteasomal degradation, which is mediated mainly by the negative regulators MDM2 and MDM4.$^{62}$ MRPL41 inhibits MDM2-mediated p53 ubiquitination and degradation and induces cell cycle arrest at $\mathrm{G}_{1} \cdot{ }^{14}$ However, a number of cellular stresses, such as DNA damage, can also stabilize $\mathrm{p} 53,{ }^{63}$ which regulates gene expression as a transcription factor, leading to apoptosis, senescence, and cell cycle arrest. ${ }^{64,65}$ As demonstrated in this study, the activation of the ATMChk2/P53-Cdk1/cyclin B1 cascade is likely one of a suite of complex cellular responses.

Higher than normal levels of ROS cause cell death; apoptosis, autophagy, and necrosis are the three main mechanisms that result in cell death. ${ }^{66}$ Apoptosis can be triggered extrinsically by receptor-mediated pathways or intrinsically by mitochondria-mediated mechanisms. ${ }^{67}$ Both intrinsic and extrinsic mechanisms are integrated to regulate cell apoptosis through mitochondria. ${ }^{68}$ Here, we showed 
that down-regulation of MRPL35 enhanced ROS-induced loss of $\Delta \Psi \mathrm{m}$, which then facilitated the release of cytochrome $c$ into the cytoplasm, the activation of the caspases, and the initiation of apoptosis. These results support the hypothesis that the loss of $\Delta \Psi \mathrm{m}$ is an early cellular response to apoptotic stimuli and plays a crucial role in mitochondria-mediated apoptosis. ${ }^{69}$ Furthermore, NAC, an ROS scavenger, significantly elevated $\Delta \Psi \mathrm{m}$ and alleviated HCT116 cell growth inhibition caused by MRPL35 knockdown, which further supported the important role of ROS in cell apoptosis.

Autophagy is a cell self-cannibalization process. ROS may also regulate autophagy through multiple signaling pathways, such as c-Jun N-terminal kinases (JNK), Akt-mTOR (mammalian target of rapamycin), and AMP-activated protein kinase (AMPK). ${ }^{70,71}$ In the nucleus, ROS sequentially activate the HIF-1 transcription factor, p53, FOXO3, and NRF2, and they in turn stimulate the transcription of BNIP3 and NIX, TIGAR, LC3, and BNIP3 and p62 to regulate autophagy. ${ }^{72}$ DRAM1 is a TP53 target gene coding a lysosomal membrane protein and has an essential role in TP53mediated autophagy activation and apoptosis. ${ }^{73-75}$ The expression of both DRAM1 and ATG5 is up-regulated because of MRPL35 knockdown in the induction of autophagy. Both DRAM1 and ATG5 are required for autophagy. ${ }^{43,76}$

It is also known that autophagy is a cell survival pathway under starvation conditions, and when cells are put under stresses such as treatment by arsenic trioxide, ${ }^{42}$ sodium selenite, ${ }^{77}$ or hypoxia, ${ }^{78}$ autophagic cell death is induced. Mounting evidence demonstrates that increase in production of ROS eventually distresses the $\Delta \Psi \mathrm{m}$ and provokes autophagic-cell death. ${ }^{42,79}$ In this study, although Z-VADFMK blocked the cleavage of caspase- 9 and caspase-3, it failed to block the cell death induced by MRPL35 knockdown to a substantial extent. This finding indicates that autophagy-dependent cell death is involved in this process. DRAM1 may also influence apoptosis through the upregulation of BAX and BAX lysosomal translocation. ${ }^{80}$ Thus, the relationship between autophagy and classic apoptosis is likely complex, and the exact mechanisms of this relationship require further investigation.

\section{Conclusion}

This work reveals an important role of MRPL35 in the development of CRC and may be a novel molecular marker for malignancy and as a prognostic indicator in CRC. However, many questions about this role await further exploration and validation.

\section{Acknowledgment}

We thank Prof. Paul Cohen (University of Rhode Island) for carefully proofreading the manuscript during revision.

\section{Supplemental Data}

Supplemental material for this article can be found at http://doi.org/10.1016/j.ajpath.2019.02.003.

\section{References}

1. Siegel R, Desantis C, Jemal A: Colorectal cancer statistics, 2014. CA Cancer J Clin 2014, 64:104-117

2. Grothey A, de Gramont A, Sargent DJ: Disease-free survival in colon cancer: still relevant after all these years! J Clin Oncol 2013, 31: $1609-1610$

3. Brandon M, Baldi P, Wallace DC: Mitochondrial mutations in cancer. Oncogene 2006, 25:4647-4662

4. Chen Y, Gibson SB: Is mitochondrial generation of reactive oxygen species a trigger for autophagy? Autophagy 2014, 4:246-248

5. Hamanaka RB, Chandel NS: Mitochondrial reactive oxygen species regulate cellular signaling and dictate biological outcomes. Trends Biochem Sci 2010, 35:505-513

6. Wallace DC: Mitochondria and cancer: Warburg addressed. Cold Spring Harb Symp Quant Biol 2005, 70:363-374

7. Wallace DC: Mitochondria and cancer. Nat Rev Cancer 2012, 12 : 685-698

8. Kenmochi N, Suzuki T, Uechi T, Magoori M, Kuniba M, Higa S, Watanabe K, Tanaka T: The human mitochondrial ribosomal protein genes: mapping of 54 genes to the chromosomes and implications for human disorders. Genomics 2001, 77:65-70

9. Gopisetty G, Thangarajan R: Mammalian mitochondrial ribosomal small subunit (MRPS) genes: a putative role in human disease. Gene 2016, 589:27-35

10. Pietromonaco SF, Denslow ND, O'Brien TW: Proteins of mammalian mitochondrial ribosomes. Biochimie 1991, 73:827-835

11. Pu M, Wang J, Huang Q, Zhao G, Xia C, Shang R, Zhang Z, Bian Z, Yang X, Tao K: High MRPS23 expression contributes to hepatocellular carcinoma proliferation and indicates poor survival outcomes. Tumour Biol 2017, 39:1010428317709127

12. Cavdar Koc E, Ranasinghe A, Burkhart W, Blackburn K, Koc H Moseley A, Spremulli LL: A new face on apoptosis: death-associated protein 3 and PDCD9 are mitochondrial ribosomal proteins. FEBS Lett 2001, 492:166-170

13. Liu CL, Luo Y, Chen L, Liu Y, Wang Y, Han J, Zhang Y, Wei N, Xie Z, Wu W, Wu G, Feng Y: MRPL33 and its splicing regulator hnRNPK are required for mitochondria function and implicated in tumor progression. Oncogene 2018, 37:86-94

14. Yoo YA, Kim MJ, Park JK, Chung YM, Lee JH, Chi SG, Kim JS, Yoo YD: Mitochondrial ribosomal protein L41 suppresses cell growth in association with p53 and p27Kip1. Mol Cell Biol 2005, 25: 6603-6616

15. Li HB, Wang RX, Jiang HB, Zhang ED, Tan JQ, Xu HZ, Zhou RR, Xia XB: Mitochondrial ribosomal protein L10 associates with cyclin B1/Cdk1 activity and mitochondrial function. DNA Cell Biol 2016 , 35:680-690

16. Chen YC, Chang MY, Shiau AL, Yo YT, Wu CL: Mitochondrial ribosomal protein $\mathrm{S} 36$ delays cell cycle progression in association with p53 modification and p21(WAF1/CIP1) expression. J Cell Biochem 2007, 100:981-990

17. Gao Y, Li F, Zhou H, Yang Y, Wu R, Chen Y, Li W, Li Y, Xu X, Ke C, Pei Z: Down-regulation of MRPS23 inhibits rat breast cancer proliferation and metastasis. Oncotarget 2017, 8:71772-71781

18. Box JM, Kaur J, Stuart RA: MrpL35, a mitospecific component of mitoribosomes, plays a key role in cytochrome c oxidase assembly. Mol Biol Cell 2017, 28:3489-3499

19. Committee for the Update of the Guide for the Care and Use of Laboratory Animals; National Research Council: Guide for the Care 
and Use of Laboratory Animals: Eighth Edition. Washington, DC, National Academies Press, 2011

20. Lamouille S, Xu J, Derynck R: Molecular mechanisms of epithelialmesenchymal transition. Nat Rev Mol Cell Biol 2014, 15:178-196

21. van Vuurden DG, Aronica E, Hulleman E, Wedekind LE, Biesmans D, Malekzadeh A, Bugiani M, Geerts D, Noske DP, Vandertop WP, Kaspers GJ, Cloos J, Wurdinger T, van der Stoop PP: Pre-B-cell leukemia homeobox interacting protein 1 is overexpressed in astrocytoma and promotes tumor cell growth and migration. Neuro Oncol 2014, 16:946-959

22. Liu H, Liu X, Zhang C, Zhu H, Xu Q, Bu Y, Lei Y: Redox imbalance in the development of colorectal cancer. J Cancer 2017, 8:1586-1597

23. Perse M: Oxidative stress in the pathogenesis of colorectal cancer: cause or consequence? Biomed Res Int 2013, 2013:725710

24. Yang Y, Karakhanova S, Werner J, Bazhin AV: Reactive oxygen species in cancer biology and anticancer therapy. Curr Med Chem 2013, 20:3677-3692

25. Fan C, Chen J, Wang Y, Wong YS, Zhang Y, Zheng W, Cao W, Chen T: Selenocystine potentiates cancer cell apoptosis induced by 5 fluorouracil by triggering reactive oxygen species-mediated DNA damage and inactivation of the ERK pathway. Free Radic Biol Med 2013, 65:305-316

26. Huang SH, Wu LW, Huang AC, Yu CC, Lien JC, Huang YP, Yang JS, Yang JH, Hsiao YP, Wood WG, Yu CS, Chung JG: Benzyl isothiocyanate (BITC) induces G2/M phase arrest and apoptosis in human melanoma A375.S2 cells through reactive oxygen species (ROS) and both mitochondria-dependent and death receptor-mediated multiple signaling pathways. J Agric Food Chem 2012, 60:665-675

27. Yeh Y-T, Hsu Y-N, Huang S-Y, Lin J-S, Chen Z-F, Chow N-H, Su S-H, Shyu H-W, Lin C-C, Huang W-T, Yeh H, Chih Y-C, Huang Y-H, Su S-J: Benzyl isothiocyanate promotes apoptosis of oral cancer cells via an acute redox stress-mediated DNA damage response. Food Chem Toxicol 2016, 97:336-345

28. Bakkenist CJ, Kastan MB: Phosphatases join kinases in DNAdamage response pathways. Trends Cell Biol 2004, 14:339-341

29. Bunz F: DNA damage signaling downstream of ATM. Edited by DeWeese T, Laiho M. In Molecular Determinants of Radiation Response. New York, NY: Springer-Verlag, 2011. pp. 35-52

30. Burma S, Chen BP, Murphy M, Kurimasa A, Chen DJ: ATM phosphorylates histone H2AX in response to DNA double-strand breaks. J Biol Chem 2001, 276:42462-42467

31. Canman CE, Lim DS, Cimprich KA, Taya Y, Tamai K, Sakaguchi K, Appella E, Kastan MB, Siliciano JD: Activation of the ATM kinase by ionizing radiation and phosphorylation of $\mathrm{p} 53$. Science 1998, 281: $1677-1679$

32. Lee JH, Paull TT: Activation and regulation of ATM kinase activity in response to DNA double-strand breaks. Oncogene 2007, 26: $7741-7748$

33. Boutros R, Lobjois V, Ducommun B: CDC25 phosphatases in cancer cells: key players? Good targets? Nat Rev Cancer 2007, 7:495-507

34. O'Connell MJ, Walworth NC, Carr AM: The G2-phase DNA-damage checkpoint. Trends Cell Biol 2000, 10:296-303

35. Campaner S, Amati B: Two sides of the Myc-induced DNA damage response: from tumor suppression to tumor maintenance. Cell Div 2012, 7:6

36. Guerra L, Albihn A, Tronnersjo S, Yan Q, Guidi R, Stenerlow B, Sterzenbach T, Josenhans C, Fox JG, Schauer DB, Thelestam M, Larsson LG, Henriksson M, Frisan T: Myc is required for activation of the ATM-dependent checkpoints in response to DNA damage. PLoS One 2010, 5:e8924

37. Lee J, Kumagai A, Dunphy WG: Positive regulation of Wee1 by Chk1 and 14-3-3 proteins. Mol Biol Cell 2001, 12:551-563

38. O'Connell MJ, Raleigh JM, Verkade HM, Nurse P: Chk1 is a wee1 kinase in the G2 DNA damage checkpoint inhibiting cdc2 by Y15 phosphorylation. EMBO J 1997, 16:545-554

39. Ly JD, Grubb DR, Lawen A: The mitochondrial membrane potential (deltapsi(m)) in apoptosis; an update. Apoptosis 2003, 8:115-128
40. Park SH, Kim JH, Chi GY, Kim GY, Chang YC, Moon SK, Nam SW, Kim WJ, Yoo YH, Choi YH: Induction of apoptosis and autophagy by sodium selenite in A549 human lung carcinoma cells through generation of reactive oxygen species. Toxicol Lett 2012, 212:252-261

41. McIlwain DR, Berger T, Mak TW: Caspase functions in cell death and disease. Cold Spring Harb Perspect Biol 2013, 5:a008656

42. Chang C-T, Korivi M, Huang H-C, Thiyagarajan V, Lin K-Y, Huang P-J, Liu J-Y, Hseu Y-C, Yang H-L: Inhibition of ROS production, autophagy or apoptosis signaling reversed the anticancer properties of Antrodia salmonea in triple-negative breast cancer (MDA-MB-231) cells. Food Chem Toxicol 2017, 103:1-17

43. Mizushima N, Yamamoto A, Hatano M, Kobayashi Y, Kabeya Y, Suzuki K, Tokuhisa T, Ohsumi Y, Yoshimori T: Dissection of autophagosome formation using Apg5-deficient mouse embryonic stem cells. J Cell Biol 2001, 152:657-668

44. Botti J, Djavaheri-Mergny M, Pilatte Y, Codogno P: Autophagy signaling and the cogwheels of cancer. Autophagy 2006, 2:67-73

45. Maiuri MC, Galluzzi L, Morselli E, Kepp O, Malik SA, Kroemer G: Autophagy regulation by p53. Curr Opin Cell Biol 2010, 22: 181-185

46. Balaburski GM, Hontz RD, Murphy ME: p53 and ARF: unexpected players in autophagy. Trends Cell Biol 2010, 20:363-369

47. O'Prey J, Skommer J, Wilkinson S, Ryan KM: Analysis of DRAM-related proteins reveals evolutionarily conserved and divergent roles in the control of autophagy. Cell Cycle 2009, 8: $2260-2265$

48. Schreuders EH, Ruco A, Rabeneck L, Schoen RE, Sung JJ, Young GP, Kuipers EJ: Colorectal cancer screening: a global overview of existing programmes. Gut 2015, 64:1637-1649

49. Vyas S, Zaganjor E, Haigis MC: Mitochondria and cancer. Cell 2016, 166:555-566

50. Srinivasan S, Guha M, Kashina A, Avadhani NG: Mitochondrial dysfunction and mitochondrial dynamics-The cancer connection. Biochim Biophys Acta 2017, 1858:602-614

51. Richter U, Lahtinen T, Marttinen P, Myohanen M, Greco D, Cannino G, Jacobs HT, Lietzen N, Nyman TA, Battersby BJ: A mitochondrial ribosomal and RNA decay pathway blocks cell proliferation. Curr Biol 2013, 23:535-541

52. Ishii T, Yasuda K, Akatsuka A, Hino O, Hartman PS, Ishii N: A mutation in the SDHC gene of complex II increases oxidative stress, resulting in apoptosis and tumorigenesis. Cancer Res 2005, 65: 203-209

53. Martinez-Cayuela M: Oxygen free radicals and human disease. Biochimie 1995, 77:147-161

54. Palchaudhuri R, Hergenrother PJ: DNA as a target for anticancer compounds: methods to determine the mode of binding and the mechanism of action. Curr Opin Biotechnol 2007, 18:497-503

55. Shiloh Y: The ATM-mediated DNA-damage response: taking shape. Trends Biochem Sci 2006, 31:402-410

56. Kang J, Ferguson D, Song H, Bassing C, Eckersdorff M, Alt FW, $\mathrm{Xu}$ Y: Functional interaction of H2AX, NBS1, and p53 in ATMdependent DNA damage responses and tumor suppression. Mol Cell Biol 2005, 25:661-670

57. Banin S, Moyal L, Shieh S, Taya Y, Anderson CW, Chessa L, Smorodinsky NI, Prives C, Reiss Y, Shiloh Y, Ziv Y: Enhanced phosphorylation of p53 by ATM in response to DNA damage. Science 1998, 281:1674-1677

58. Shiloh Y, Kastan MB: ATM: genome stability, neuronal development, and cancer cross paths. Adv Cancer Res 2001, 83:209-254

59. Malumbres M, Barbacid M: Mammalian cyclin-dependent kinases. Trends Biochem Sci 2005, 30:630-641

60. Hara M, Abe Y, Tanaka T, Yamamoto T, Okumura E, Kishimoto T: Greatwall kinase and cyclin B-Cdk1 are both critical constituents of M-phase-promoting factor. Nat Commun 2012, 3:1059

61. Levine AJ, Oren M: The first 30 years of p53: growing ever more complex. Nat Rev Cancer 2009, 9:749-758 
62. Marine JC, Francoz S, Maetens M, Wahl G, Toledo F, Lozano G: Keeping p53 in check: essential and synergistic functions of Mdm2 and Mdm4. Cell Death Differ 2006, 13:927-934

63. Vousden KH, Lane DP: p53 in health and disease. Nat Rev Mol Cell Biol 2007, 8:275-283

64. Fridman JS, Lowe SW: Control of apoptosis by p53. Oncogene 2003, 22:9030-9040

65. Riley T, Sontag E, Chen P, Levine A: Transcriptional control of human p53-regulated genes. Nat Rev Mol Cell Biol 2008, 9:402-412

66. Lin S, Li Y, Zamyatnin AA Jr, Werner J, Bazhin AV: Reactive oxygen species and colorectal cancer. J Cell Physiol 2018, 233: $5119-5132$

67. Riedl SJ, Shi Y: Molecular mechanisms of caspase regulation during apoptosis. Nat Rev Mol Cell Biol 2004, 5:897-907

68. Redza-Dutordoir M, Averill-Bates DA: Activation of apoptosis signalling pathways by reactive oxygen species. Biochim Biophys Acta 2016, 1863:2977-2992

69. Henry-Mowatt J, Dive C, Martinou JC, James D: Role of mitochondrial membrane permeabilization in apoptosis and cancer. Oncogene 2004, 23:2850-2860

70. Djavaheri-Mergny M, Amelotti M, Mathieu J, Besancon F, Bauvy C, Souquere S, Pierron G, Codogno P: NF-kappaB activation represses tumor necrosis factor-alpha-induced autophagy. J Biol Chem 2006, 281:30373-30382

71. Huang Q, Wu YT, Tan HL, Ong CN, Shen HM: A novel function of poly(ADP-ribose) polymerase-1 in modulation of autophagy and necrosis under oxidative stress. Cell Death Differ 2009, 16:264-277

72. Li L, Tan J, Miao Y, Lei P, Zhang Q: ROS and autophagy: interactions and molecular regulatory mechanisms. Cell Mol Neurobiol 2015, 35:615-621
73. Crighton D, Wilkinson S, Ryan KM: DRAM links autophagy to p53 and programmed cell death. Autophagy 2007, 3:72-74

74. Crighton D, Wilkinson S, O'Prey J, Syed N, Smith P, Harrison PR, Gasco M, Garrone O, Crook T, Ryan KM: DRAM, a p53-induced modulator of autophagy, is critical for apoptosis. Cell 2006, 126: $121-134$

75. Takahashi M, Kakudo Y, Takahashi S, Sakamoto Y, Kato S, Ishioka C: Overexpression of DRAM enhances p53-dependent apoptosis. Cancer Med 2013, 2:1-10

76. Kuma A, Hatano M, Matsui M, Yamamoto A, Nakaya H, Yoshimori T, Ohsumi Y, Tokuhisa T, Mizushima N: The role of autophagy during the early neonatal starvation period. Nature 2004, 432:1032-1036

77. Kim EH, Sohn S, Kwon HJ, Kim SU, Kim MJ, Lee SJ, Choi KS: Sodium selenite induces superoxide-mediated mitochondrial damage and subsequent autophagic cell death in malignant glioma cells. Cancer Res 2007, 67:6314-6324

78. Azad MB, Chen Y, Henson ES, Cizeau J, McMillan-Ward E, Israels SJ, Gibson SB: Hypoxia induces autophagic cell death in apoptosis-competent cells through a mechanism involving BNIP3. Autophagy 2008, 4:195-204

79. D'Anneo A, Carlisi D, Lauricella M, Puleio R, Martinez R, Di Bella S, Di Marco P, Emanuele S, Di Fiore R, Guercio A, Vento R, Tesoriere G: Parthenolide generates reactive oxygen species and autophagy in MDA-MB231 cells. A soluble parthenolide analogue inhibits tumour growth and metastasis in a xenograft model of breast cancer. Cell Death Dis 2013, 4:e891

80. Guan JJ, Zhang XD, Sun W, Qi L, Wu JC, Qin ZH: DRAM1 regulates apoptosis through increasing protein levels and lysosomal localization of BAX. Cell Death Dis 2015, 6:e1624 